\title{
Effects of atmospheric dynamics and aerosols on the fraction of supercooled water clouds
}

\author{
Jiming Li ${ }^{1}$, Qiaoyi Lv ${ }^{1}$, Min Zhang ${ }^{1}$, Tianhe Wang ${ }^{1}$, Kazuaki Kawamoto ${ }^{2}$, Siyu Chen ${ }^{1}$, and Beidou Zhang ${ }^{1}$ \\ ${ }^{1}$ Key Laboratory for Semi-Arid Climate Change of the Ministry of Education, College of Atmospheric Sciences, \\ Lanzhou University, Lanzhou, China \\ ${ }^{2}$ Graduate School of Fisheries Science and Environmental Studies, Nagasaki University, Nagasaki, Japan \\ Correspondence to: Jiming Li (lijiming @lzu.edu.cn)
}

Received: 16 February 2016 - Discussion started: 25 February 2016

Revised: 27 December 2016 - Accepted: 19 January 2017 - Published: 8 February 2017

\begin{abstract}
Based on 8 years of (January 2008December 2015) cloud phase information from the GCM-Oriented Cloud-Aerosol Lidar and Infrared Pathfinder Satellite Observation (CALIPSO) Cloud Product (GOCCP), aerosol products from CALIPSO and meteorological parameters from the ERA-Interim products, the present study investigates the effects of atmospheric dynamics on the supercooled liquid cloud fraction (SCF) during nighttime under different aerosol loadings at global scale to better understand the conditions of supercooled liquid water gradually transforming to ice phase.

Statistical results indicate that aerosols' effect on nucleation cannot fully explain all SCF changes, especially in those regions where aerosols' effect on nucleation is not a first-order influence (e.g., due to low ice nuclei aerosol frequency). By performing the temporal and spatial correlations between SCFs and different meteorological factors, this study presents specifically the relationship between SCF and different meteorological parameters under different aerosol loadings on a global scale. We find that the SCFs almost decrease with increasing of aerosol loading, and the SCF variation is closely related to the meteorological parameters but their temporal relationship is not stable and varies with the different regions, seasons and isotherm levels. Obviously negative temporal correlations between SCFs versus vertical velocity and relative humidity indicate that the higher vertical velocity and relative humidity the smaller SCFs. However, the patterns of temporal correlation for lower-tropospheric static stability, skin temperature and horizontal wind are relatively more complex than those of vertical velocity and humidity. For example, their close correlations are predomi-
\end{abstract}

nantly located in middle and high latitudes and vary with latitude or surface type. Although these statistical correlations have not been used to establish a certain causal relationship, our results may provide a unique point of view on the phase change of mixed-phase cloud and have potential implications for further improving the parameterization of the cloud phase and determining the climate feedbacks.

\section{Introduction}

Cloud feedbacks are recognized as the greatest source of uncertainty in the climate change predictions projected by climate models (Boucher et al., 2013). One of the outstanding challenges to better understanding the role of clouds in future climate change involves how to more accurately determine the cloud phase composition between 0 and $-40^{\circ} \mathrm{C}$ (Tsushima et al., 2006; McCoy et al., 2015; Tan et al., 2016). As we know, clouds are composed entirely of liquid or ice particles when temperatures are above the freezing $\left(0^{\circ} \mathrm{C}\right)$ or below homogeneous freezing (approximately $-40^{\circ} \mathrm{C}$ ), respectively (Pruppacher and Klett, 1997). Between 0 and $-40^{\circ} \mathrm{C}$, clouds may consist of pure ice, liquid particles or both (that is, mixed-phase). If the temperature of liquid water cloud is lower than $0^{\circ} \mathrm{C}$, we consider it to be supercooled water cloud. The proper partitioning of cloud phase is very critical for the calculation of cloud radiative properties due to differences of cloud liquid and ice in refractive indices, sizes, concentration and shapes (Sun and Shine, 1994). For example, by assessing the radiative transfer impacts of mixedphase clouds, Sassen and Khvorostyanov (2007) showed that 
the total cloud radiative impact of mixed-phase clouds decreases as supercooled clouds glaciate. In addition, the phase composition also has an important impact on the cloud precipitation efficiency and lifetime (Pinto, 1998; Jiang et al., 2000).

Generally speaking, the changes of cloud phase composition in mixed-phase clouds is complicatedly controlled by several factors other than temperature, e.g., ice nuclei (IN) (Choi et al., 2010; Tan et al., 2014; Zhang et al., 2015) or dynamical processes (Trembly et al., 1996; Shupe et al., 2008). Some special aerosols suspended in the atmosphere can change the cloud phase by acting as IN in the heterogeneous ice nucleation process of mixed-phase clouds via different nucleation modes (e.g., deposition, immersion freezing, contact and condensation freezing) (Lohmann and Feichter, 2005). For example, based on laboratory experiments and field measurements, mineral dust from arid regions has been widely recognized as an important source of IN in mixed-phase clouds because of its nucleation efficiency and abundance in the atmosphere. In addition to dust, some studies have also verified the potential ice nucleation ability of polluted dust and smoke at cold temperatures (Niedermeier et al., 2011; Cziczo et al., 2013; Tan et al., 2014; Zhang et al., 2015). For dynamical process, Naud et al. (2006) assessed the impact of large-scale ascent on the cloud phase and found that the areas of greatest large-scale ascent are not glaciated at cloud top as much as areas of moderate ascent. If largeor meso-scale models are unable to appropriately resolve these microphysical and dynamical processes, they will fail to accurately separate the cloud phase composition, which further affect the major climate feedbacks of global climate models by changing cloud, water vapor, lapse rate and surface albedo (Choi et al., 2014). For example, by conducting a multi-model intercomparison of cloud-water in five stateof-the-art atmospheric general circulation models (AGCMs), Tsushima et al. (2006) found that the difference in mixedphase cloud algorithms among different models can result in different poleward redistribution of cloud liquid water, therefore causing the difference in albedo feedback in the models. Those models which have less cloud ice in the mixed-phase layer will lead to higher climate sensitivity due to the positive solar cloud feedback. It is therefore of fundamental importance to know the spatiotemporal distributions of different cloud phases, especially supercooled liquid clouds, and their variation with the IN or environmental conditions changing to improve the simulation of mixed-phase clouds in the current climate models and reduce uncertainties in-cloud feedback within models.

Compared with the passive remote sensing (Huang et al., 2005, 2006a), the millimeter-wavelength cloud-profiling radar (CPR) on CloudSat (Stephens et al., 2002) and the Cloud-Aerosol Lidar with Orthogonal Polarization (CALIOP) (Winker et al., 2007) on Cloud-Aerosol Lidar and Infrared Pathfinder Satellite Observation (CALIPSO) can provide more detailed data regarding the vertical structure of clouds, along with cloud phase information on a global scale (Hu et al., 2010; Li et al., 2010, 2015; Lv et al., 2015). The depolarization ratio and layer-integrated backscatter intensity measurements from CALIOP can help distinguish cloud phases (Hu et al., 2007, 2009). For example, by using combined cloud phase information from CALIOP and temperature measurement from Imaging Infrared Radiometer (IIR), Hu et al. (2010) compiled the global statistics regarding the occurrence, liquid water content and fraction of supercooled liquid clouds. Based on the vertically resolved observations of clouds and aerosols from CALIOP, Choi et al. (2010) and Tan et al. (2014) analyzed the variation of supercooled water cloud fraction and possible dust aerosol impacts at given temperatures. For dynamic processes, although some studies have focused on the impacts of large-scale meteorological parameters on supercooled water cloud fraction at regional scale based on observation (Naud et al., 2006) or global scale in observations and models (Cesana et al., 2015), related studies of the statistical relationship between cloud phase changes and meteorological parameters under different aerosol loadings have received far less attention. For the above reasons, this study combines cloud phase information from the GCM-Oriented CALIPSO Cloud Product (GOCCP) (Chepfer et al., 2010), meteorological parameters from ERA-Interim reanalysis datasets and the aerosol product from CALIPSO to investigate the correlations between supercooled liquid cloud fraction (SCF) and meteorological parameters under different aerosol loadings at a global scale.

This paper is organized as follows: a brief introduction to all datasets used in this study is given in Sect. 2. Section 3.1 outlines the global distributions and seasonal variations of SCFs and IN aerosol (here, dust, polluted dust and smoke). Further analyses regarding the temporal and spatial correlations between SCFs and meteorological parameters are provided in Sects. 3.2 and 3.3. Important conclusions and discussions are presented in Sect. 4.

\section{Datasets and methods}

In the current study, 8 years (January 2008-December 2015) of data from CALIPSO-GOCCP, the ERA-Interim daily product (Dee et al., 2011) and the CALIPSO level $25 \mathrm{~km}$ aerosol layer product are collected to analyze the effects of meteorological parameters on the SCFs under different aerosol loadings at a global scale.

\subsection{Cloud phase product}

Currently, several methods have been presented to determine the thermodynamic phase at the cloud top based on lidaronly or combined radar-lidar signals. For radar-lidar cloud phase products, DARDAR (Delanoe and Hogan, 2010) and CloudSat 2B-CLDCLASS-lidar (Zhang et al., 2010) cloud phase products take advantage of the combination of lidar 
backscatter and radar reflectivity to distinguish ice clouds, typical mixed-phase clouds, where a liquid top overlies the ice, and liquid clouds. However, the lidar-only method discriminates cloud phase based on the following physical basis. That is, nonspherical particles (e.g., ice crystal) can change the state of polarization of the laser light backscattered and result in large values of the cross-polarization component $\left(\mathrm{ATB}_{\perp}\right)$ of attenuated backscattered signal (ATB), whereas spherical particles (e.g., liquid droplets) do not if the effects of multiple scattering are neglected.

As a lidar-only cloud climatology, the main goal of CALIPSO-GOCCP climatology is to facilitate the evaluation of clouds in climate models (e.g., Cesana and Chepfer, 2012; Cesana et al., 2015) with the joint use of the CALIPSO simulator (Chepfer et al., 2008). Thus, GOCCP has been designed to diagnose cloud properties from CALIPSO observations in same way (e.g., similar spatial resolution, same criteria for cloud detection and statistical cloud diagnostics) as in the CALIPSO simulator included in the Cloud Feedback Model Intercomparison Project (CFMIP, http://www.cfmip. net) Observation Simulator Package (COSP) used within version 2 of the CFMIP (CFMIP-2) experiment (BodasSalcedo et al., 2011). This ensures the differences of the observations and the "model + simulator" ensemble outputs are mostly attributed to model biases (e.g., Cesana et al., 2012; Cesana and Chepfer, 2012). The CALIPSO-GOCCP cloud algorithm includes following steps. First, the instantaneous profile of the lidar attenuated scattering ratio (SR) at a vertical resolution of $480 \mathrm{~m}$ is generated from every CALIPSO level 1 lidar profile (horizontal resolution of $333 \mathrm{~m}$ ). Here, SR is the ratio of the total ATB to the computed molecular attenuated backscattered signal $\left(\mathrm{ATB}_{\mathrm{mol}}\right.$, only molecules). Then, each atmospheric layer is labeled as cloudy (SR $\geq 5$ and ATB-ATB ${ }_{\text {mol }}>2.5 \times 10^{-3} \mathrm{~km}^{-1} \mathrm{sr}^{-1}$ ), clear $(0.01 \leq \mathrm{SR}<1.2)$, fully attenuated $(\mathrm{SR}<0.01)$ or uncertain pixel $(1.2 \leq \mathrm{SR}<5)$ to construct the three-dimensional cloud fraction. However, it is worth noting that a threshold of 5 for SR in CALIPSO-GOCCP cloud algorithm may miss some subvisible clouds (optical depth $<0.03$ ) and result in the underestimation of optical thin cloud layers (e.g., Chepfer et al., 2013). Some dense dust or smoke layers also can be misclassified as cloudy pixels (Chepfer et al., 2010). For every cloudy pixel, CALIPSO-GOCCP product further classifies as "ice", "liquid" or "undefined" sample by using the 2-D histograms of $\mathrm{ATB}, \mathrm{ATB}_{\perp}$ and a phase discrimination line (Cesana and Chepfer, 2013). Those "undefined" samples include three ambiguous parts: (1) cloudy pixels located at lower altitudes than a cloudy pixel with SR $>30$, (2) cloudy pixels with abnormal value of depolarization (e.g., $\mathrm{ATB}_{\perp}<0$ or $\left.\mathrm{ATB}_{\perp} /\left(\mathrm{ATB}-\mathrm{ATB}_{\perp}\right)>1\right)$ and (3) horizontally oriented ice particles. Cesana and Chepfer (2013) indicated that these "undefined" samples account for about $10.3 \%$ of cloudy pixels in 15 months of global statistics. In addition, because lidar cannot penetrate optically thick clouds (optical depth $>3$, such as the supercooled liquid layer in the polar region) to de- tect ice crystals (Zhang et al., 2010), the CALIPSO-GOCCP cloud phase products possibly lead to a slight underestimation of ice clouds at the lowest levels at Arctic (Cesana et al., 2016).

In the present analysis, the cloud phase information during nighttime is derived from the 3D_CloudFraction_Phase_temp monthly average dataset in the CALIPSO-GOCCP v2.9 cloud product. This dataset includes cloud fractions for all clouds ("cltemp"), liquid ("cltemp_liq"), ice clouds ("cltemp_ice") and undefined clouds ("cltemp_un") as a function of the temperature in each longitude-latitude grid box $\left(2^{\circ} \times 2^{\circ}\right)$. In addition, the temperature used here is obtained from GMAO (Global Modeling and Assimilation Office; Bey et al., 2001), which is part of the CALIPSO level 1 ancillary data. For each CALIOP level 1 profile, the GMAO temperature is interpolated over the $480 \mathrm{~m}$ vertical levels of CALIPSO-GOCCP as the cloudy pixel temperature. That is, the temperature bins are ranged every $3{ }^{\circ} \mathrm{C}$ and 38 temperature bins are provided for each parameter. Those liquid phase clouds whose high bounds of temperature bins are lower than $0^{\circ} \mathrm{C}$ are considered as supercooled water phase clouds. Similar to the definition of SCF from Choi et al. (2010) and Tan et al. (2014), we calculate the SCF at a given temperature bin (or isotherm) as the ratio of the cltemp_liq/(cltemp_liq + cltemp_ice) in a $2^{\circ} \times 2^{\circ}$ grid box. Because there are no $-10,-20$ and $-30^{\circ} \mathrm{C}$ isotherms in the CALIPSO-GOCCP product, the present study utilizes the 22 nd (from -27 to $-30^{\circ} \mathrm{C}$ ), 25 th (from -18 to $-21^{\circ} \mathrm{C}$ ) and 28 th (from -9 to $-12^{\circ} \mathrm{C}$ ) temperature bins to represent $-30,-20$ and $-10^{\circ} \mathrm{C}$ isotherms, respectively. Choi et al. (2010) has pointed out that this definition may lead to some overestimation of SCFs without considering horizontally oriented ice particles, which account for about $10 \%$ of the uncertainty in their study. However, the impact of the oriented ice crystals on the determination of cloud phase is negligible after tilting the CALIOP to $3^{\circ}$ off-nadir (November 2007) (Hu et al., 2009; Cesana et al., 2016).

\subsection{Meteorological reanalysis dataset}

The ERA-Interim reanalysis daily $6 \mathrm{~h}$ products are also used here to provide the related information of meteorological parameters at the surface and several pressure levels, including the skin temperature, surface pressure and $2 \mathrm{~m}$ air temperature at surface level, vertical velocity at $500 \mathrm{hPa}$ level, the $U$ component of wind at $100 \mathrm{hPa}$ level, temperature at $700 \mathrm{hPa}$ level and relative humidity at three levels $(400,500$ and $600 \mathrm{hPa}$ ). Note that all these variables are matched with the CALIPSO aerosol product in space and time to perform correlation analyses with SCFs in Sects. 3.2 and 3.3. Here, the $700 \mathrm{hPa}$ temperature, surface and $2 \mathrm{~m}$ air temperature are used to calculate the lower-tropospheric static stability (LTSS), which is defined as the difference in potential temperature between $700 \mathrm{hPa}$ and the surface (Klein and Hart- 

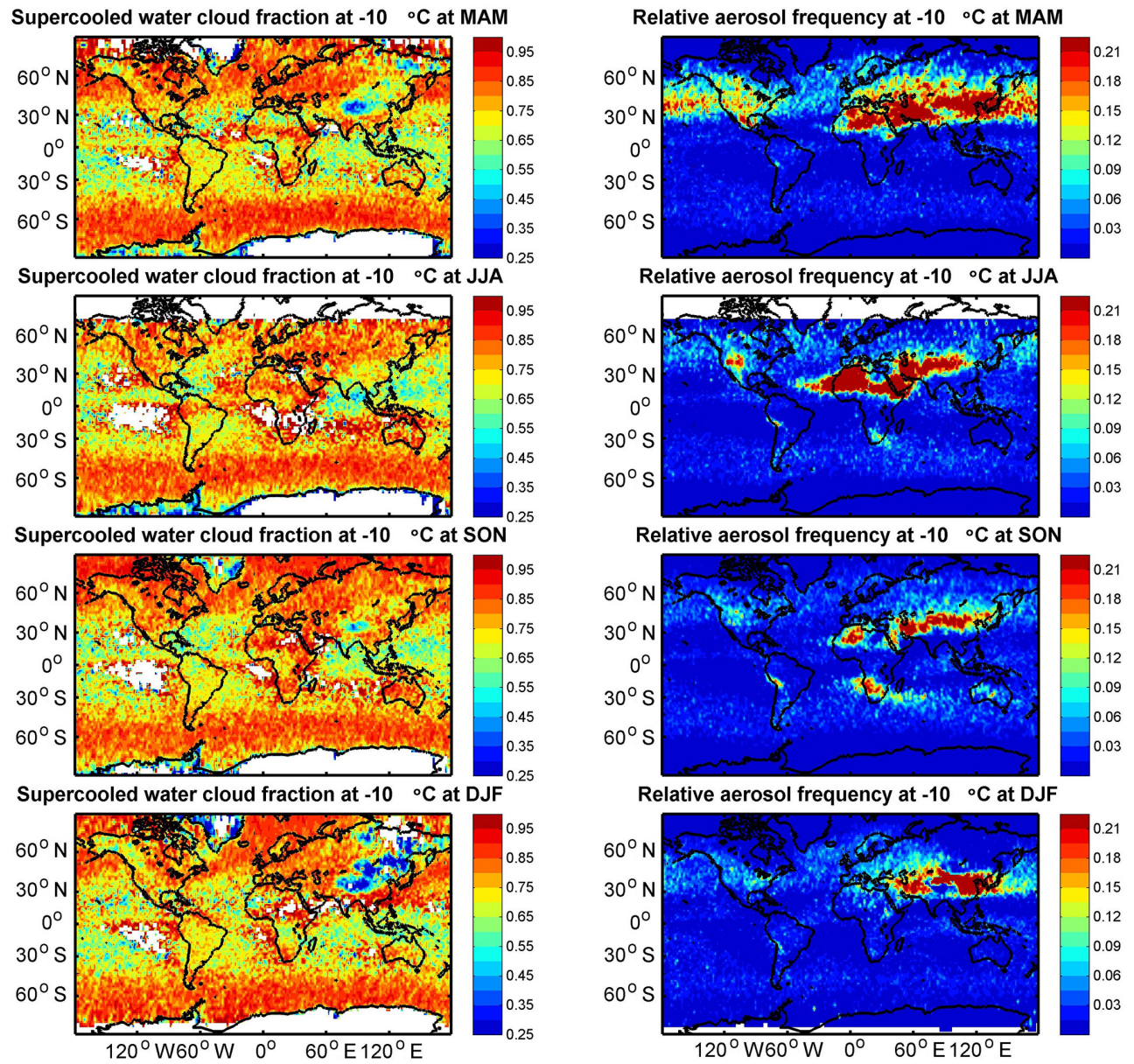

Figure 1. The global and seasonal variations of supercooled water cloud fractions (SCFs) and relative aerosol frequencies (RAFs) during nighttime at $-10^{\circ} \mathrm{C}$ isotherm over $2^{\circ} \times 2^{\circ}$ grid boxes.

mann, 1993), as described below:

$\Delta \theta=T_{700}\left[\frac{1000}{p_{700}}\right]^{R / C_{p}}-T_{\mathrm{sfc}}\left[\frac{1000}{p_{\mathrm{sfc}}}\right]^{R / C_{p}}$

where $p$ presents pressure, $T$ is temperature and $R$ and $C_{p}$ denote the gas constant of air and the specific heat capacity at a constant pressure, respectively. Note that a high LTSS value represents a stable atmosphere and the positive vertical velocity implies updraft in this study, and vice versa. In addition, it needs further noting that the vertical velocity used in this investigation is referred to the large-scale vertical motion and is different from the in-cloud updrafts velocity mentioned in previous studies (Rauber and Tokay, 1991; Tremblay et al., 1996; Shupe at al., 2006).

\subsection{Aerosol types and relative frequency}

Aerosol data are obtained from the CALIPSO level $25 \mathrm{~km}$ aerosol layer product. Using scene classification algorithms, CALIPSO first classifies the atmospheric feature layer as either a cloud or aerosol by using the mean attenuated backscatter coefficients at $532 / 1064 \mathrm{~nm}$, along with the color ratio (Liu et al., 2009). A confidence level for each feature layer is also supplied by the level 2 products. Using the surface type, lidar depolarization ratio, integrated attenuated backscattering coefficient and layer elevation, aerosols are further distinguished as desert dust, smoke, polluted dust, clean continental aerosol, polluted continental aerosol and marine aerosol (Omar et al., 2009). Mielonen et al. (2009) used a series of sun photometers from the Aerosol Robotic Network (AERONET) to compare CALIOP and AERONET aerosol types and found that $70 \%$ of the aerosol types from these two datasets are similar, especially for the dust and polluted dust types. In the following analysis, we calculate the total relative occurrence frequency (RAF) of IN aerosol types by combining the dust, polluted dust and smoke information from CALIPSO here. Given the difficulty of quantifying the concentration of IN aerosols, the relative occurrence frequency can be used as a proxy of the concentration of aerosols (Choi et al., 2010). In addition, those aerosol layers with low confidence values (feature type QA flag is "low" 

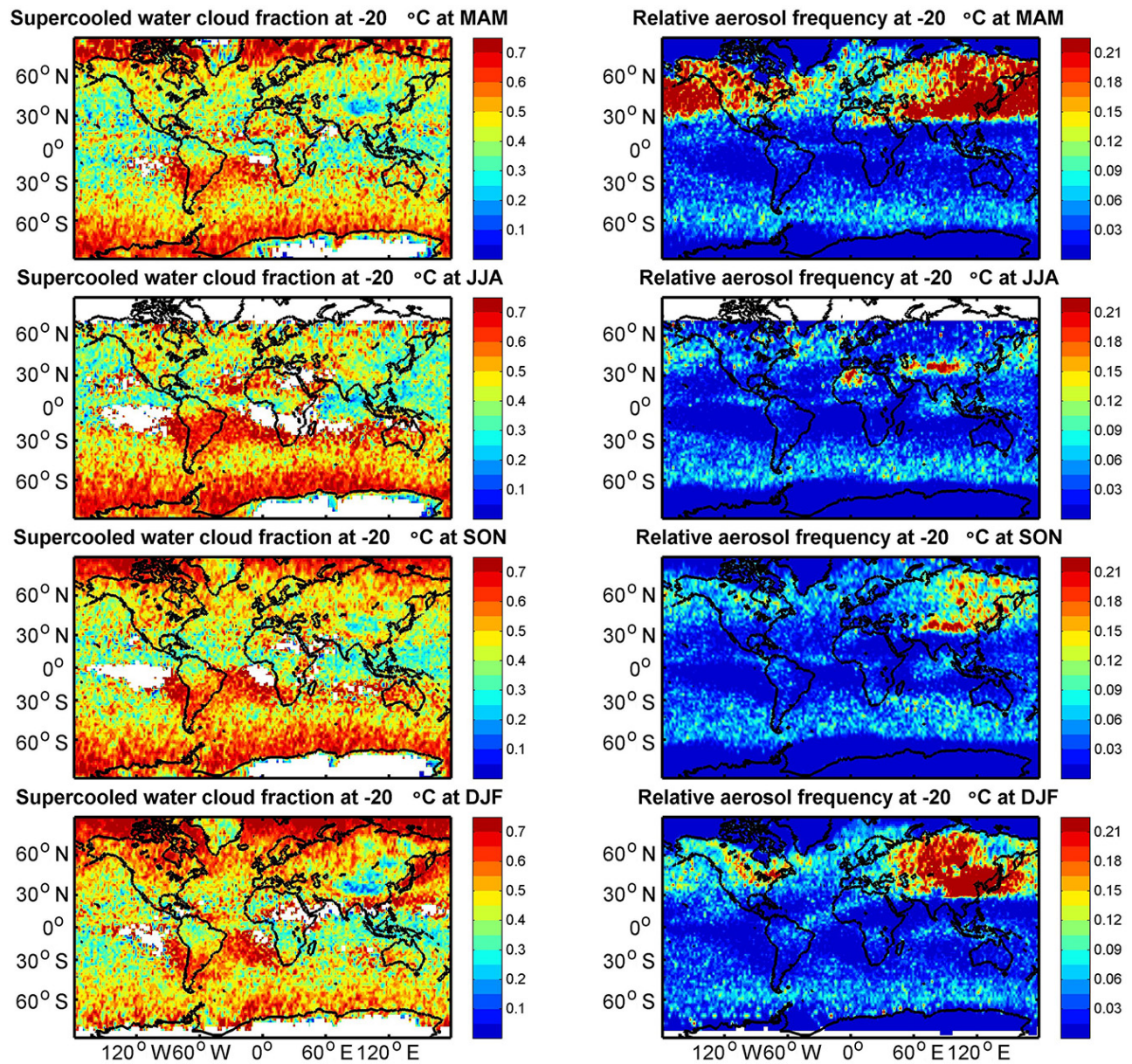

Figure 2. The global and seasonal variations of supercooled water cloud fractions (SCFs) and relative aerosol frequencies (RAFs) during nighttime at $-20^{\circ} \mathrm{C}$ isotherm over $2^{\circ} \times 2^{\circ}$ grid boxes.

in aerosol product) are removed from the dataset (approximately $6 \%$ of all aerosol layers). Meanwhile, GMAO temperature of aerosol layer top is also used here to select consistent temperature bins with the CALIPSO-GOCCP cloud product. For every IN aerosol sample, we arrange a temperature bin based on its layer-top temperature. Then, we define the frequency of IN aerosols at a given temperature bin as the ratio of the number of IN aerosol samples to the total number of observation profiles for the same temperature bin and grid (Choi et al., 2010). Finally, the relative occurrence frequencies of IN aerosols are calculated by normalizing aerosol frequencies. That is, aerosol frequencies are divided by the highest aerosol frequency at a given isotherm (that is, temperature bin). The RAF is thus indicative of the temporal and spatial variability of IN aerosols compared to the maximum occurrence frequency (Choi et al., 2010).

Furthermore, considering the sparse sample data for the narrow CALIOP orbit, we reduce the horizontal resolution from 2 to $6^{\circ}$ for ensuring enough samples in each grid box when analyzing the relationship between SCFs and meteorological parameters under different aerosol loadings
(Sect. 3.2). To avoid artifacts due to noise from scattering of sunlight, only the nighttime datasets of cloud phase, meteorological parameters and aerosol are used to perform following analysis.

\section{Results}

\subsection{Global and seasonal distributions of 8-year average SCFs and RAFs}

Based on the statistical results of the 8-year CALIPSOGOCCP cloud phase product and CALIPSO level $25 \mathrm{~km}$ aerosol layer product, the global distributions and seasonal variations of SCFs and the RAFs of aerosol at three isotherms, i.e., $-10,-20$ and $-30^{\circ} \mathrm{C}$, at a $2^{\circ}$ latitude by $2^{\circ}$ longitude resolution are provided in Figs. 1-3, respectively. At the $-10{ }^{\circ} \mathrm{C}$ isotherm (Fig. 1), supercooled water cloud fractions are large at middle and high latitudes of two hemispheres. Especially, the SCFs exceed $75 \%$ over the high latitudes (poleward of $60^{\circ}$ ) during all seasons except for over 

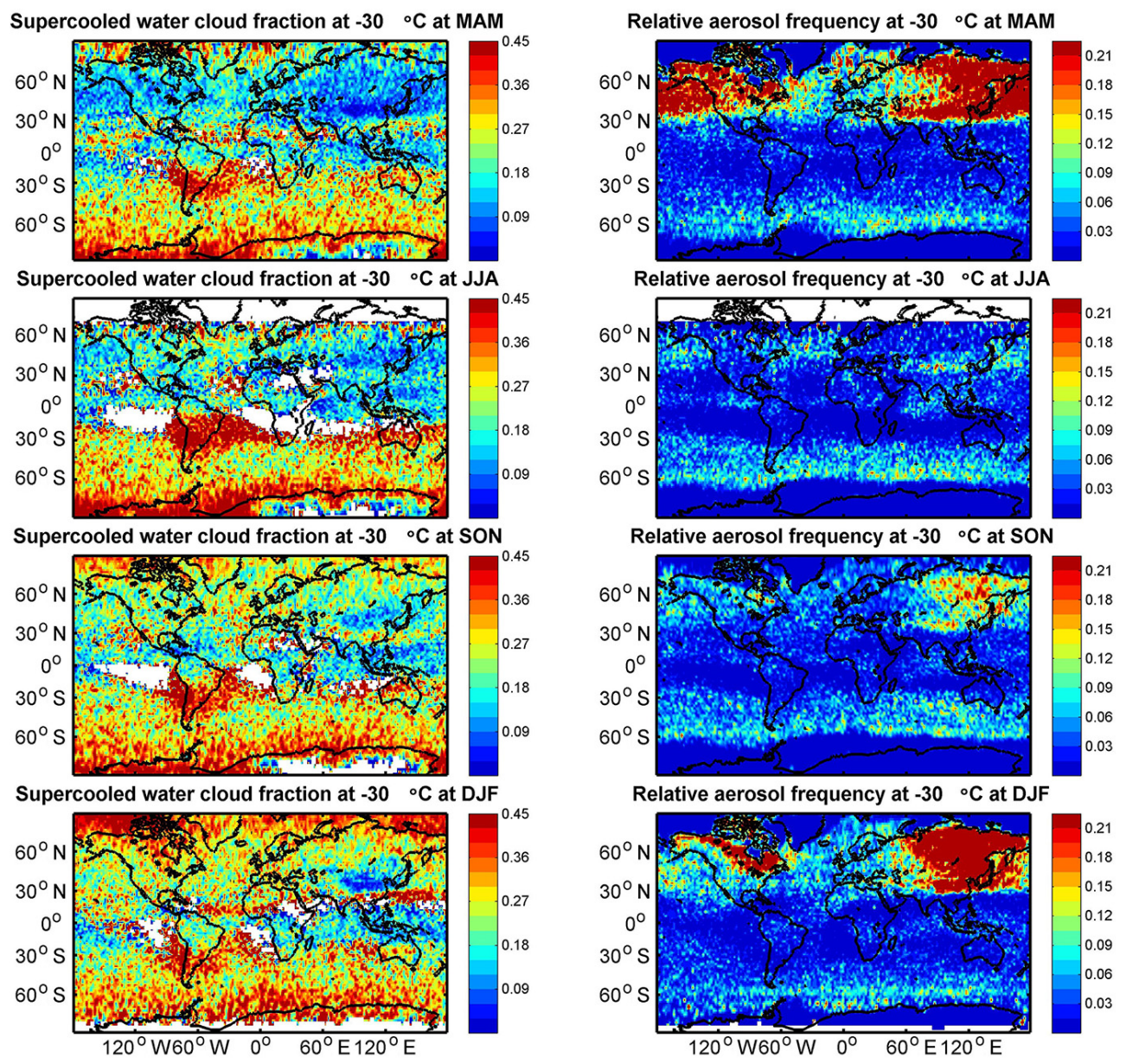

Figure 3. The global and seasonal variations of supercooled water cloud fractions (SCFs) and relative aerosol frequencies (RAFs) during nighttime at $-30^{\circ} \mathrm{C}$ isotherm over $2^{\circ} \times 2^{\circ}$ grid boxes.

Greenland. The SCFs between $30^{\circ} \mathrm{N}$ and $30^{\circ} \mathrm{S}$ range from approximately 55 to $75 \%$; the lowest SCFs $(<40 \%)$ are predominantly located in mainland China during boreal winter season, mostly in northwestern and northeastern parts of China. For relative aerosol frequency at the $-10^{\circ} \mathrm{C}$ isotherm, its global distributions are expected and large RAFs are predominantly located in the dust source regions, i.e., Saharan and Taklamakan deserts, where dust relative frequencies are greater than $20 \%$ during boreal summer and spring, respectively. The "aerosol belt" near the US (between 30 and $60^{\circ} \mathrm{N}$ ) during boreal spring is mostly from the long-range transport of dust from the Taklamakan Desert, which travels across the Pacific Ocean to the US via westerlies (Huang et al., 2008). In addition, Saharan dust can also be transported by trade winds across the Atlantic to the US and the Caribbean. At the -20 and $-30^{\circ} \mathrm{C}$ isotherms, the spatial patterns of SCFs are similar to those results at $-10^{\circ} \mathrm{C}$ and SCFs are lower at -20 and $-30^{\circ} \mathrm{C}$ than at $-10^{\circ} \mathrm{C}$. However, the seasonal variation of SCFs at -20 and $-30^{\circ} \mathrm{C}$ is more obvious compared with those results at $-10^{\circ} \mathrm{C}$, especially at high latitudes of the Northern Hemisphere. For RAFs, however, the comparison between different isotherms is not meaningful because the RAFs are normalized relative to each fixed isotherm. Thus, larger RAF at -20 or $-30^{\circ} \mathrm{C}$ than at $-10^{\circ} \mathrm{C}$ does not mean that the true aerosol frequency at -20 or $-30^{\circ} \mathrm{C}$ is really higher than values at $-10^{\circ} \mathrm{C}$. Compared with the RAFs at the $-10^{\circ} \mathrm{C}$ isotherms, the "aerosol belt" between 30 and $60^{\circ}$ for two hemispheres at the -20 or $-30^{\circ} \mathrm{C}$ isotherms is more apparent. Previous studies have verified that the regional differences in the SCFs at $-20^{\circ} \mathrm{C}$ or other isotherms are highly anticorrelated with the dust frequency above the freezing level (Choi et al., 2010; Tan et al., 2014). However, based on Figs. 1-3, we find that this is not always the case for all regions. For example, by analyzing the zonal means of SCF and RAF at $-20^{\circ} \mathrm{C}$ (Fig. 4), we find that the SCF still has a low value $(\mathrm{SCF}<0.45)$ at the midlatitudes of the Northern Hemisphere during the summer season, even though the IN aerosol loading is significantly low $(\mathrm{RAF}<0.05)$ over this region during summer season. The obvious seasonal variations of SCFs over these regions seem to not be explicitly matched the seasonal variation of aerosol frequency. These results indicate that the aerosols' effect on nucleation cannot fully ex- 

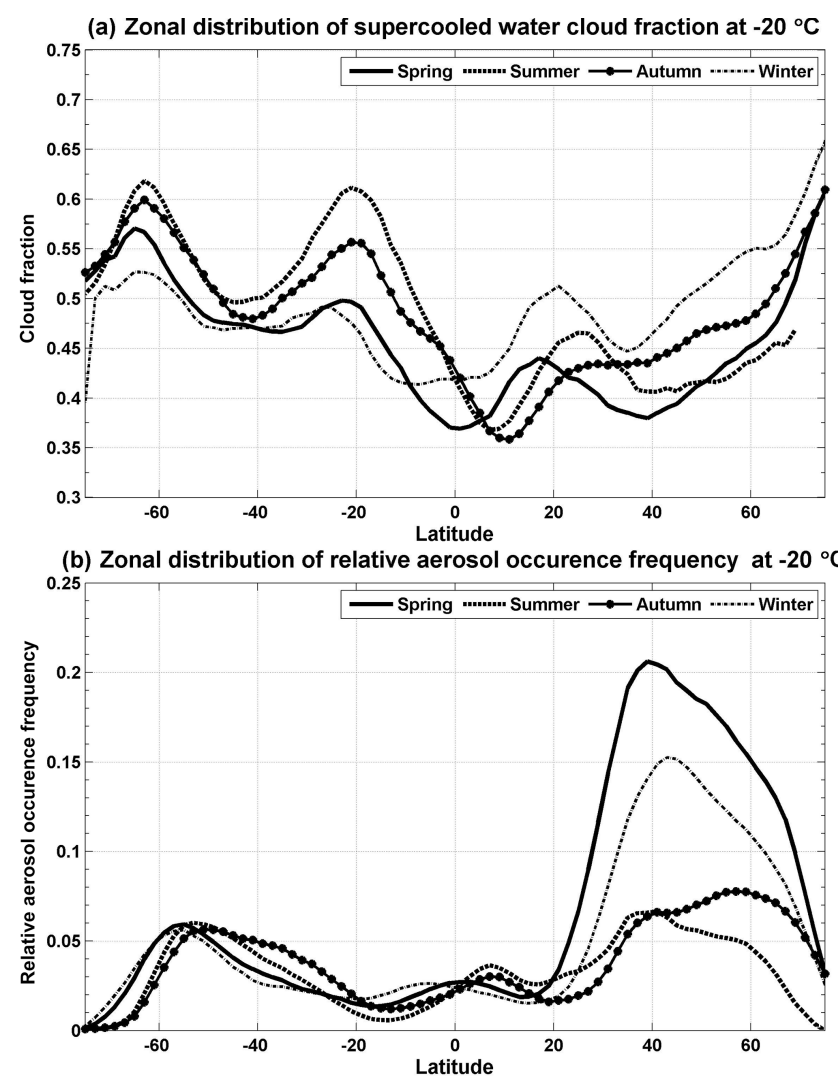

Figure 4. The zonal and seasonal variations of SCFs and RAFs during nighttime at $-20^{\circ} \mathrm{C}$ isotherm.

plain all changes of the supercooled liquid cloud fraction in our study, especially its regional and seasonal variations. In other words, there is no evidence to suggest that the aerosol effect is always dominant at each isotherm or region. Then, can these variations of SCF attribute to the meteorological effect? If yes, what is the role of meteorological parameters on the cloud phase change, especially at those regions in which the aerosol effect on nucleation is not first-order due to low IN aerosol frequency? In the following section, temporal and spatial correlation analysis between SCFs and meteorological parameters is conducted to help discuss these questions.

\subsection{Temporal correlations between SCFs and meteorological parameters}

The synoptical-scale dynamics is the first-order variable driving the formation of clouds and their properties (Noel et al., 2010). Aside from temperature, some past theoretical studies and observations already verified that the in-cloud updraft motions can supply a plentiful of water vapor for the persistence of cloud liquid, thus playing an important role in the cloud phase partitioning in mixed-phase clouds (Rauber and Tokay, 1991; Tremblay et al., 1996; Shupe at al., 2006). A sufficient updraft can be sourced by cloud top entrainment of dry air, radiative cooling, wing shear, larger-scale insta- bilities and surface turbulent heat fluxes (Pinto, 1998; Moeng, 2000). In addition, Naud et al. (2006) also indicated that glaciation of supercooled water drops may be a function of the large-scale vertical motions, precipitation, development stage of cloud and concentration of IN. In this section, we investigate the potential correlations between largescale meteorological parameters and SCFs over the 8-year period (96 months). Although these statistical correlations do not imply complete causation, we expect that these results may provide a unique point of view on the phase change of mixed-phase cloud.

In view of the issue of a sparse dataset caused by the narrow orbit of CALIOP, we perform the correlation analysis at $6^{\circ}$ latitude by $6^{\circ}$ longitude grid boxes. Firstly, we calculate the monthly averages of SCF, meteorological parameters and RAFs at different isotherms (or pressure levels) in each $6^{\circ}$ latitude by $6^{\circ}$ longitude grid box by using the following equation:

$\bar{M}=\left(\sum_{i=1}^{9} w_{i} \times M_{i}\right) / \sum_{i=1}^{9} w_{i}$,

where $M_{i}$ is the averaged SCF or meteorological parameter of the $i$ th $2^{\circ} \times 2^{\circ}$ grid box in this $6^{\circ} \times 6^{\circ}$ geographic region, and $w_{i}=\cos \left(\theta_{i} \times \pi / 180.0\right)$; here $\theta_{i}$ is the mean latitude of the $i$ th $2^{\circ} \times 2^{\circ}$ grid. Then, temporal correlations between monthly averaged SCFs and meteorological parameters are performed in each $6^{\circ}$ latitude by $6^{\circ}$ longitude grid box. It is worth noting that only those grid boxes whose temporal correlations are at the $90 \%$ confidence level are displayed in the following global maps and are used further to discuss the spatial correlation in Sect. 3.3.

Figure 5 shows the global distributions of temporal correlations between SCFs at three isotherms $(-10,-20$ and $-30^{\circ} \mathrm{C}$ ) and skin temperature, with vertical velocity at $500 \mathrm{hPa}$. For skin temperature (left panel), temporal correlation coefficients have obvious regional differences. For example, at the $-10^{\circ} \mathrm{C}$ isotherm, negative temporal correlations mainly locate in ocean regions between $60^{\circ} \mathrm{S}$ and $60^{\circ} \mathrm{N}$, whereas the positive correlations can be found in the South Pole, mainland China and Greenland. The positive correlation implies that seasonal cycles of skin temperature are consistent with those of SCF, whereas negative correlation indicates that their seasonal cycles are opposite. In the tropics, high skin temperature tends to trigger tropical deep convection easily. Bower et al. (1996) found that the vigorous in-cloud updrafts in convective clouds do not leave enough time for supercooled droplets to transform into ice crystals, thus suppressing ice formation or pushing supercooled liquid water to a colder cloud top height. West et al. (2014) concluded that the sub-grid vertical velocity enhancing leads to an increase of the liquid water path. Some studies also verified the importance of in-cloud vertical motions for supporting the growth of liquid water in Arctic mixed-phase clouds (Shupe et al., 2006, 2008). However, our results show that the 


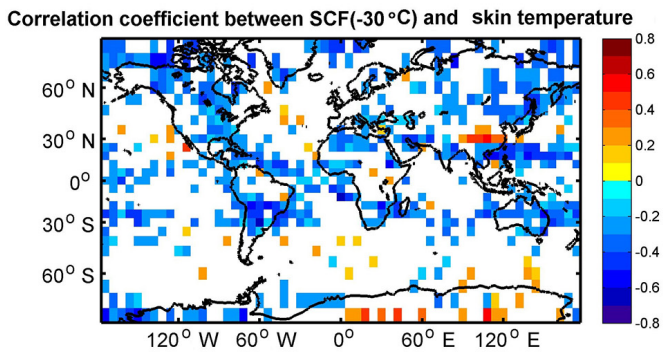

Correlation coefficient between $\operatorname{SCF}\left(-20^{\circ} \mathrm{C}\right)$ and skin temperature
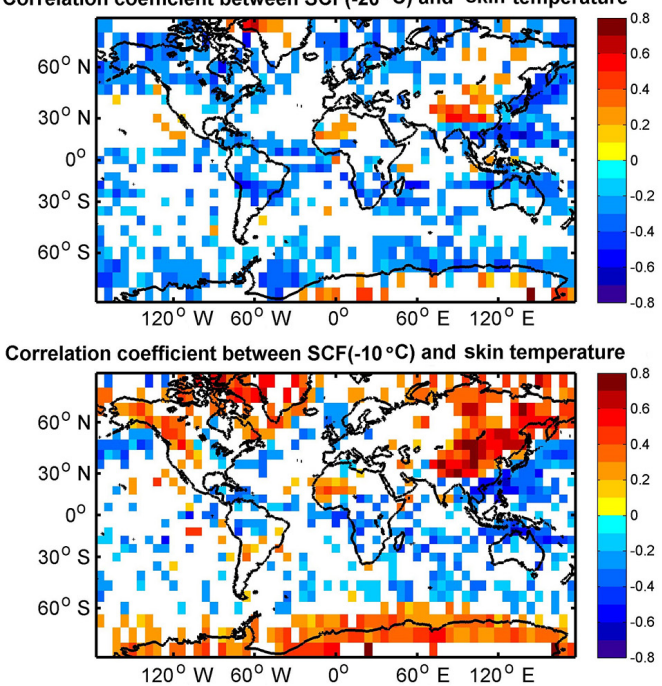

Correlation coefficient between $\operatorname{SCF}\left(-30^{\circ} \mathrm{C}\right)$ and vertical velocity $(500 \mathrm{hPa})$

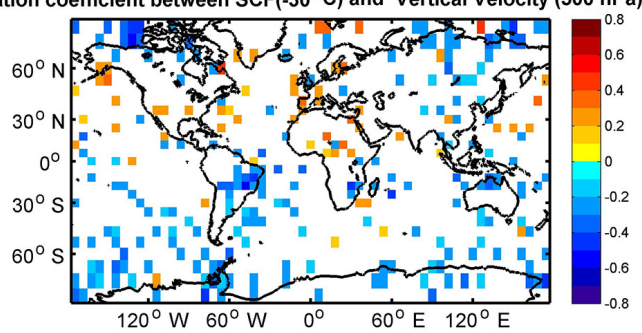

Correlation coefficient between $\operatorname{SCF}\left(-20^{\circ} \mathrm{C}\right)$ and vertical velocity $(500 \mathrm{hPa})$

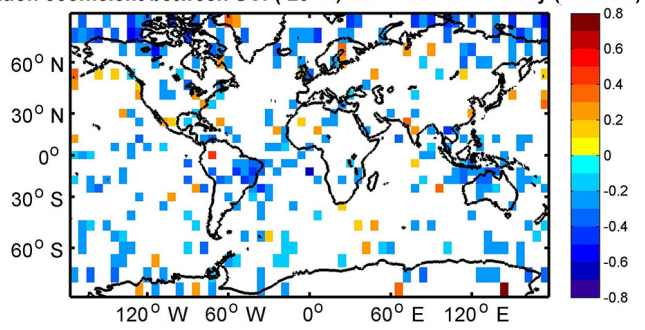

Correlation coefficient between $\operatorname{SCF}\left(-10^{\circ} \mathrm{C}\right)$ and vertical velocity $(500 \mathrm{hPa})$

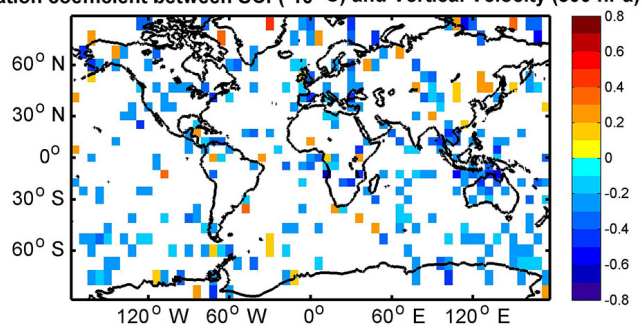

Figure 5. Temporal correlations (at the $90 \%$ confidence level) between SCFs at three isotherms and skin temperature (left panel) and vertical velocity at $500 \mathrm{hPa}$ (right panel). The correlations are based on 96 months' monthly SCFs and meteorological parameters. Grid size is $6^{\circ}$ latitude by $6^{\circ}$ longitude.

warm sea surface temperature and large-scale ascent (right panel of Fig. 5) are in favor of the ice formation. This result is consistent with the study from Cesana et al. (2015), which found updrafts correspond to slightly warmer cloud phase transition than those downdrafts, and this relationship also can be found at different latitudes. Indeed, it is clear that the negative temporal correlations between SCFs and the vertical velocity at $500 \mathrm{hPa}$ exist at almost all latitudes although grid boxes are considerably scattered. This might be because large-scale ascent in this study smooths many cloudscale vertical motions. At middle latitudes, we also find a negative correlation between SCF and surface temperature except for mainland China. By analyzing the frontal clouds over the midlatitudes of the Northern Hemisphere, Naud et al. (2006) pointed out that the changes in glaciation temperature of supercooled liquid cloud appear to be related to the sea surface temperature (SST) pattern, storm vertical velocity and strength. Glaciation of supercooled liquid cloud is likely to occur preferentially in the storm region where the warmer SST occurs. In these warm regions (e.g., tropics), strong precipitation rates may exhaust the supercooled liquid drops. Their finding possible partially explains the negative correlations between SCF and skin temperature at the midlatitudes and tropical region in our study. However, statistical results show that positive correlations between SCF at $-10{ }^{\circ} \mathrm{C}$ isotherm and surface temperature exist at middle and high latitudes (e.g., mainland China and Antarctica), but seasonal cycles of surface temperature at these two latitudinal zones are similar. It shows that SCFs at middle and high latitudes have inverse seasonal variations, which is unable fully interpreted by the surface temperature. By analyzing the time series of other parameters, the opposite seasonal variations of SCF at these two latitudinal zones seem are correlated with their atmospheric stability (e.g., LTSS). At high latitudes of Southern Hemisphere, the vertical motion is relatively weak and the atmosphere is stable (high LTSS); thereby weak motion cannot supply sufficient moist to the liquid layer of mixed-phase cloud. With decreasing temperature (e.g., at the $-20^{\circ} \mathrm{C}$ isotherm), the negative temporal correlation coefficients between SCFs and skin temperature are more obvious at middle and high latitudes. However, the correlations disappear or vary from positive to negative values at $-30^{\circ} \mathrm{C}$ isotherm, which are also seen in Figs. 6 and 7. This is mainly due to the fact that the seasonal cycles of SCF at this isotherm are unapparent or even opposite to other isotherms (especially over the northeastern part of China). 


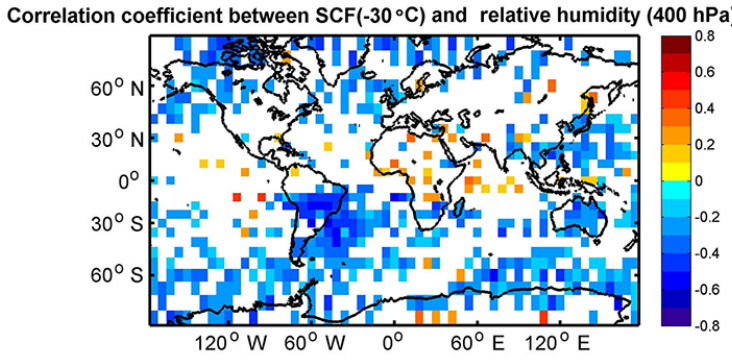

Correlation coefficient between $\mathrm{SCF}\left(-20^{\circ} \mathrm{C}\right)$ and relative humidity $(500 \mathrm{hPa})$

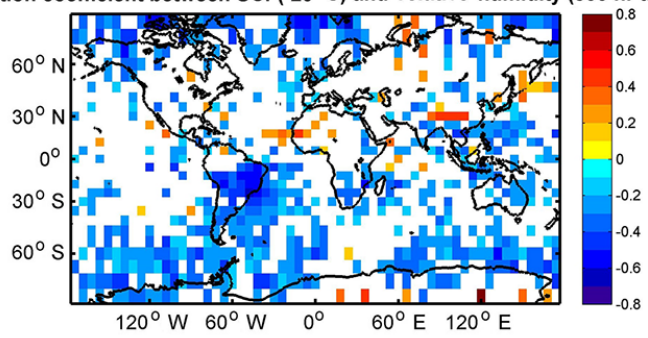

Correlation coefficient between $\mathrm{SCF}\left(-10^{\circ} \mathrm{C}\right)$ and relative humidity $(600 \mathrm{hPa})$

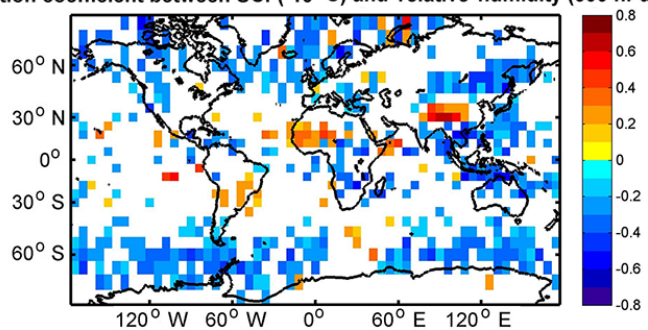

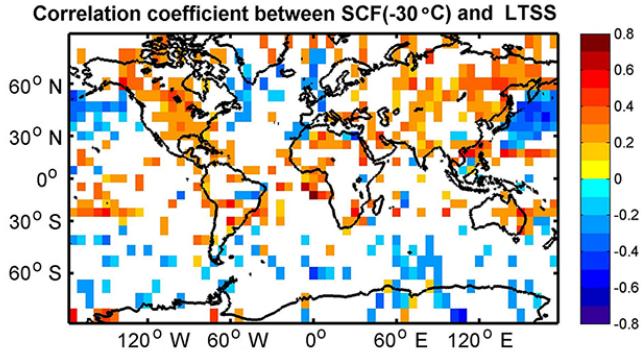
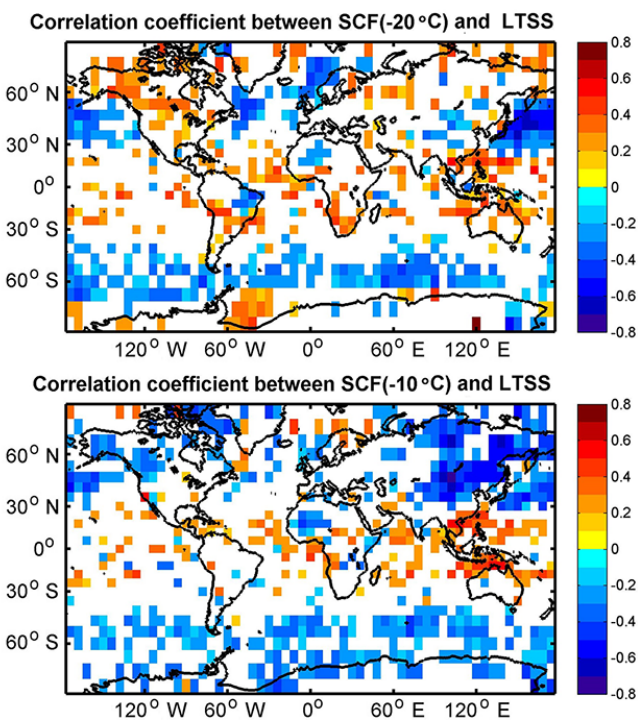

Figure 6. Similar to Fig. 5 but for relative humidity (left panel) and LTSS (right panel).

Similar to Fig. 5, Fig. 6 shows the temporal correlations between SCFs at three isotherms and LTSS, relative humidity at three pressure levels $(400,500$ and $600 \mathrm{hPa})$. It is clear that SCFs at different regions and isotherms apparently negatively correlate with humidity. By analyzing the time series of perturbation for SCF and humidity (figure not shown), we find that their correlation is still obvious. It means that SCFs decrease as the relative humidity increases without regard to their region. This result also is consistent with study form Cesana et al. (2015). Besides the humidity, there is also obvious correlation between SCFs and LTSS (right panel of Fig. 6). We can see that the negative correlations between SCFs and LTSS mainly locate at the ocean region. It means that SCF is low in a stable low level atmosphere. For the horizontal wind speed at $100 \mathrm{hPa}$, Noel et al. (2010) found that the frequency of oriented crystal drops severely in areas dominated by stronger horizontal wind speed at $100 \mathrm{hPa}$. This effect is especially noticeable at latitudes below $40^{\circ}$. However, they have not explained why the correlation between horizontal wind speed and horizontally oriented ice particle is negative. We speculate that strong horizontal wind possibly results in strong vertical wind shear, thus causing shear-gravitational wave motions to induce local updraft circulations (Rauber and Tokay, 1991). As a result, updraft possibly perturbs the orientation of ice crystal. In addition, Westbrook et al. (2010) pointed out that supercooled liquid water layers is very important in the formation of planar ice particles, which are susceptible to orientation at midlatitudes. Based on these studies, we assume that the temporal correlation between SCF and zonal wind speed also exists. Indeed, stronger winds are correlated with an increase in SCFs at different isotherms for ocean region of middle latitudes, whereas negative correlations also exist in central Africa, the Tibetan Plateau or poleward regions of $60^{\circ} \mathrm{S}$ (see Fig. 7). All this being said, this section presents specifically the relationship between SCF and different meteorological parameters on a global scale relative to some previous studies (e.g., Naud et al., 2006) which mainly focused on special regions, although we have not established a certain causal relationship in the present study. Noticeably, our statistical results demonstrate that the SCF variation is closely related to the meteorological parameters but their relationship is not stable and varies with the different regions, seasons and isotherm levels and thus should be treated carefully in the prediction of future climate change.

Furthermore, we select three regions to represent different aerosol loadings and investigate their temporal variations of SCFs, meteorological parameters and RAFs of IN aerosol in several selected regions in Figs. 8-10, respectively. Note that each line in every subplot corresponds to a time series of different variables after 5-month moving average, but the 

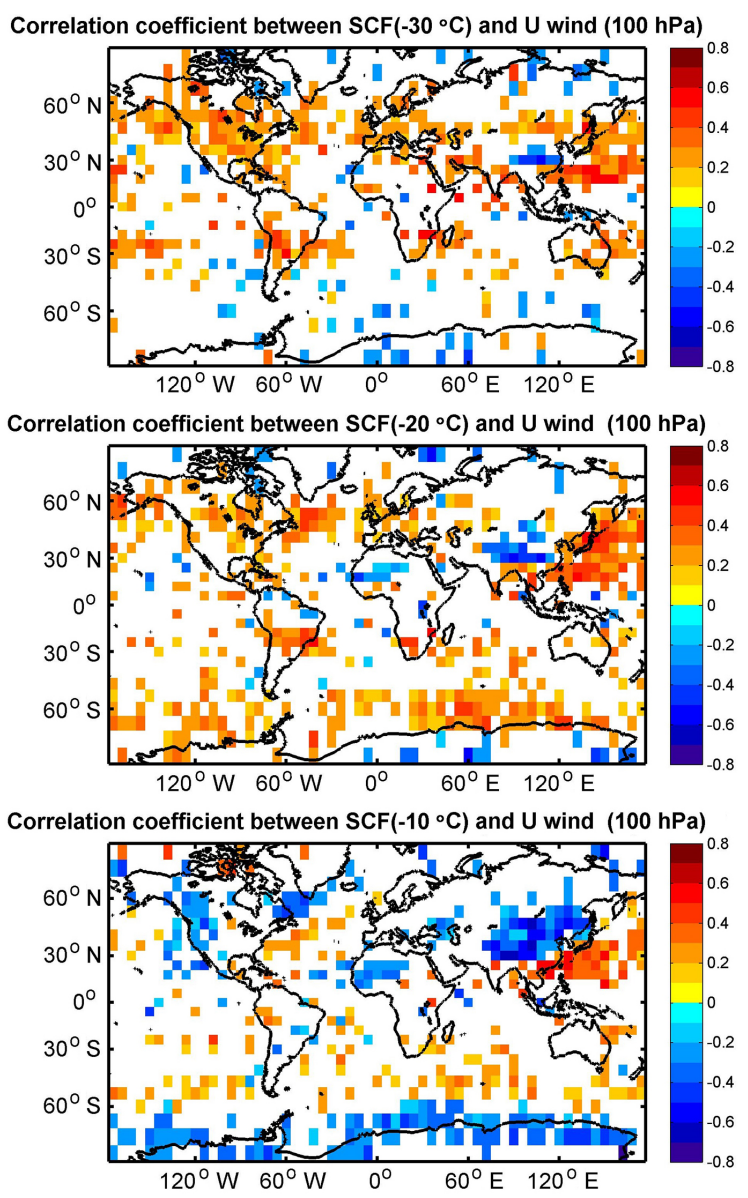

Figure 7. Similar to Fig. 5 but for $U$ wind at $100 \mathrm{hPa}$.

temporal correlation coefficients in the subplots of Figs. 810 are calculated based on the original series, which has a greater than $90 \%$ confidence level. We also provide the confidence value (i.e., $p$ value) when the confidence level of the temporal correlation between variables is less than $90 \%$. Figure 8 shows the time series of various variables at the $-30^{\circ} \mathrm{C}$ isotherm over the central China $\left(102-108^{\circ} \mathrm{E}, 30\right.$ $36^{\circ} \mathrm{N}$ ), which is near to the Taklamakan Desert. High frequencies of dust and polluted dust in this region peak during the months when SCFs are at minimum with the correlation coefficient of -0.42 . Negative correlations also exist between SCF and LTSS (or horizontal wind at $100 \mathrm{hPa}$ ); their values are -0.17 and -0.53 , respectively. In addition, the skin temperature over this region also display a coherent seasonal variation with the SCFs $($ corrcoef $=0.58)$. At the $-10^{\circ} \mathrm{C}$ isotherm over a region near the Antarctic (174$180^{\circ} \mathrm{E}, 66-72^{\circ} \mathrm{S}$ ), the RAFs of aerosol are persistently low $(<0.02)$ for 96 months (see Fig. 9). The correlation coefficient between SCF and RAF is only -0.09 , and its confidence level is very low $(P=0.39)$. The seasonal variations of SCF over this region are consistent with the meteorological parameters. For example, their correlation coefficients are $0.22,-0.18$ and -0.18 for skin temperature, LTSS and $U$ wind, respectively. The third region is located over the Southern Ocean $\left(116-122^{\circ} \mathrm{E}, 18-24^{\circ} \mathrm{N}\right)$, where the maximum RAF of aerosol at the $-20^{\circ} \mathrm{C}$ isotherm can reach 0.05 (see Fig. 10). Skin temperature and LTSS have negative correlations with SCF ( -0.59 and 0.51 , respectively), whereas a positive temporal correlation exists between SCF and $U$ wind (approximately 0.45). These statistical results further indicate that the same meteorological parameter has a distinct correlation with SCFs in different regions.

\subsection{Spatial correlations between SCFs and meteorological parameters}

In this section, we further investigate the spatial correlations of SCF and different meteorological parameters under different aerosol loadings. As the correlations between SCFs and aerosol frequencies are less likely to be statistically significant in the Southern Hemisphere and tropics due to far fewer aerosols compared to the Northern Hemisphere, we only provide the global results. Here, each meteorological factor of grids is grouped into six bins based on its values within a specified aerosol loading level. In the present study, the aerosol loadings are divided into three levels based on relative aerosol frequencies. The three aerosol levels are high level (RAF $>0.05)$, middle level $(0<\mathrm{RAF}<0.05)$ and low level $(\mathrm{RAF}=0)$. Such grouping ensures a sufficient number of samples available in each bin (at least several hundreds of samples in each bin) to satisfy statistical significance. Moreover, note that only regions with temporal correlations of SCFs and meteorological parameters greater than the $90 \%$ confidence level are used to calculate the spatial correlations between SCFs and meteorological parameters.

Figure 11 shows clearly the different spatial correlations between SCF at the $-20^{\circ} \mathrm{C}$ isotherm and the meteorological parameters. The error bars correspond to the \pm 5 standard error (SE). Here, the $\mathrm{SE}$ is computed as $\mathrm{SE}=\mathrm{SD} / \sqrt{N}$, where $\mathrm{SD}$ is the standard deviation of the data falling in a meteorological parameter bin (e.g., vertical velocity $<20 \mathrm{hPa} \mathrm{day}^{-1}$ ) and aerosol loading level; $N$ is the sample number in each bin. At a fixed isotherm (such as $-20^{\circ} \mathrm{C}$ ), we can see that the aerosol is obviously anticorrelated with SCFs at a global scale. That is, the SCFs almost decrease with increasing RAF. This result is consistent with the previous study of Tan et al. (2014), which demonstrated that SCFs and RAFs of dust, polluted dust and smoke are not only temporally negatively correlated but also spatially negatively correlated. In Fig. 11, we find that SCFs and $500 \mathrm{hPa}$ vertical velocity (or surface skin temperature) have a significantly negative correlation spatially at the $90 \%$ confidence level under different aerosol loading. By performing a similar analysis at different aerosol thresholds, we confirm this conclusion. The spatial correlation coefficients between SCFs and meteorological parameters at three isotherms are summarized in Table 1. For the relative humidity (Fig. 11b), the SCFs decrease 

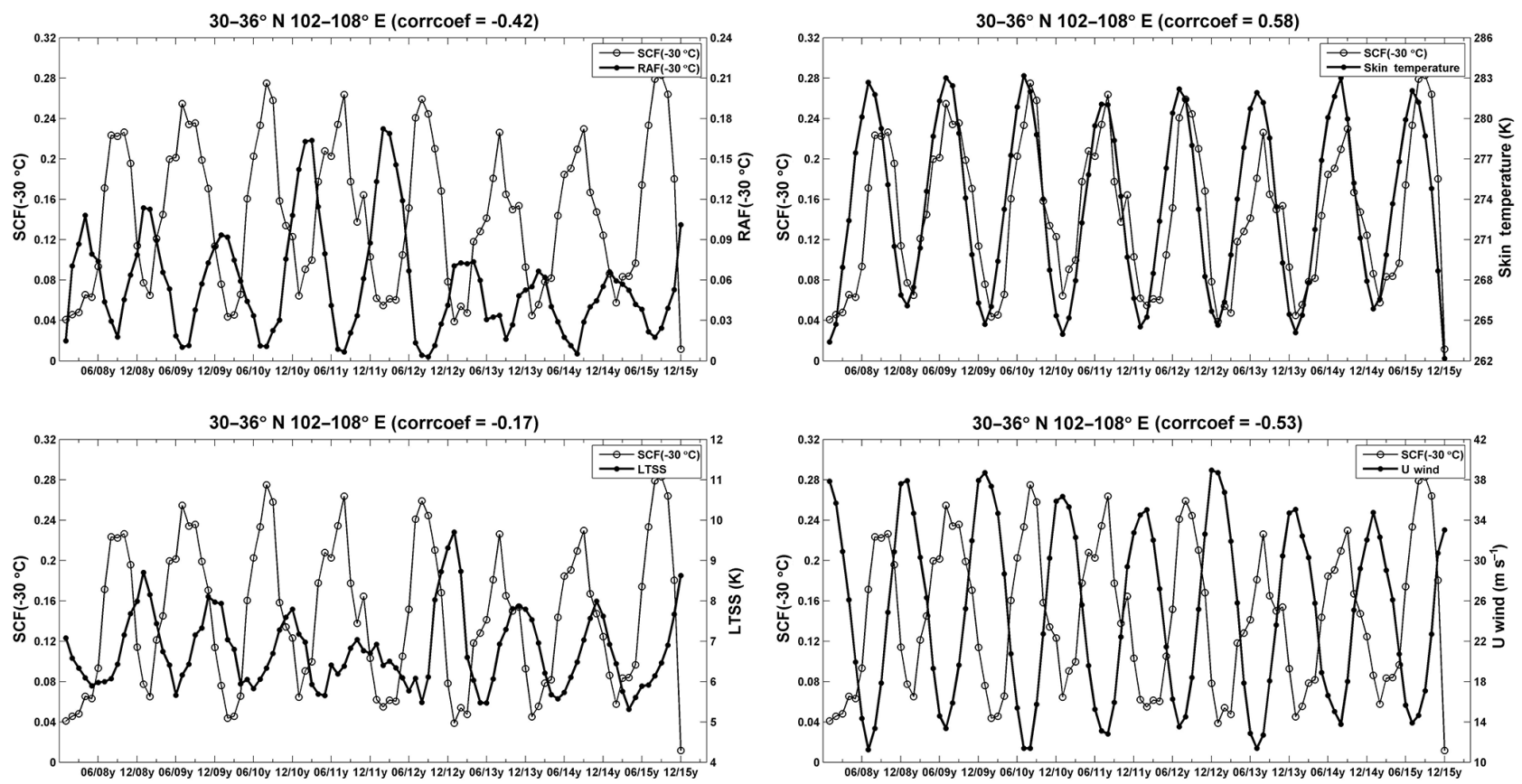

Figure 8. Time series plots of SCFs, meteorological parameters and RAFs of IN aerosol at $-30{ }^{\circ} \mathrm{C}$ isotherm over the central China $(102-$ $\left.108^{\circ} \mathrm{E}, 30-36^{\circ} \mathrm{N}\right)$. Each line in every subplot corresponds to a time series of different variables after 5 months of smoothing. The coefficients (at the $90 \%$ confidence level) in subplots represent the temporal correlation between the original SCFs series and meteorological parameters (or RAFs). The confidence values (i.e., $p$ value) are provided only when the confidence level of the temporal correlation between variables is less than $90 \%$.
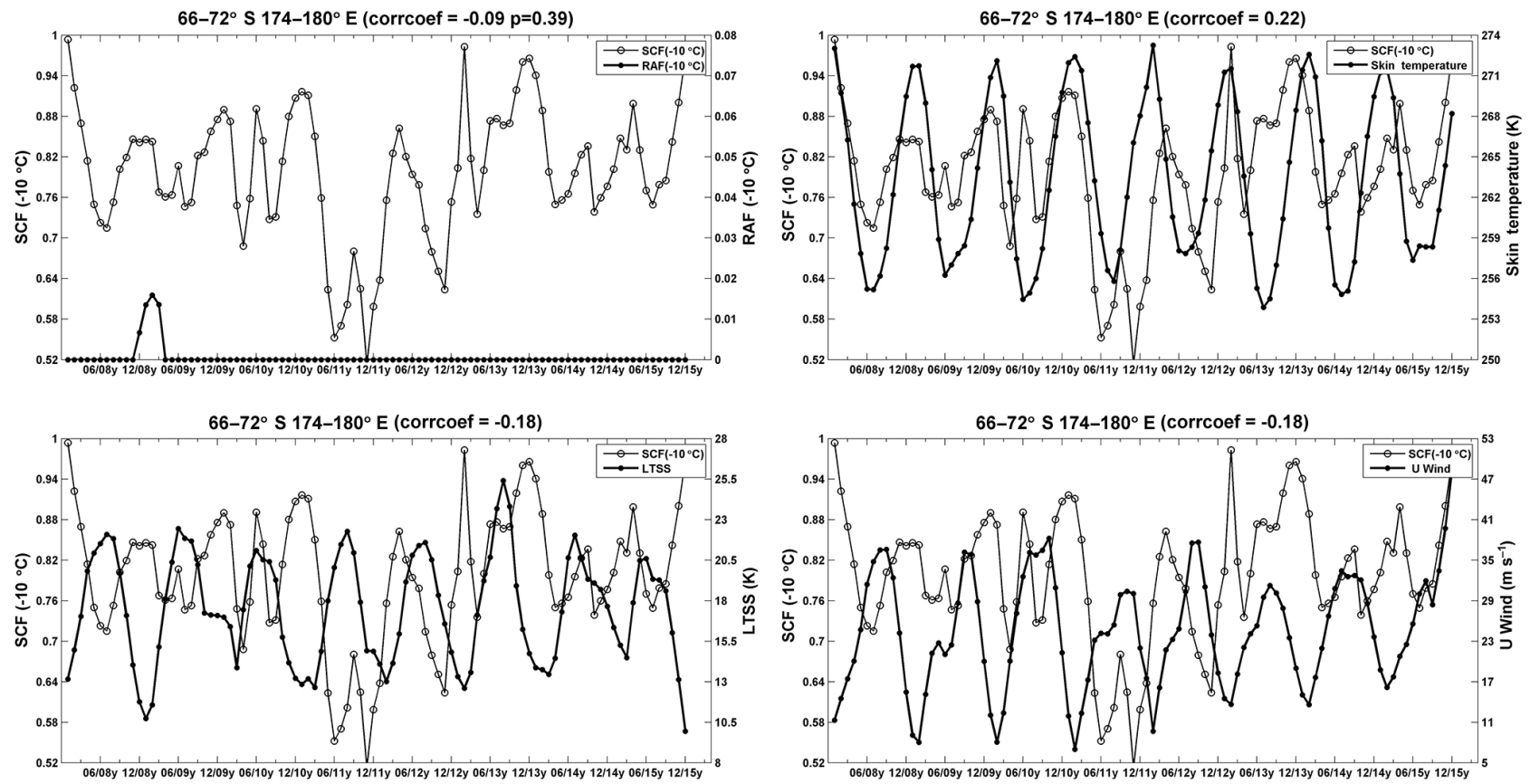

Figure 9. Similar to Fig. 8 but for $-10^{\circ} \mathrm{C}$ isotherm near the Antarctic $\left(174-180^{\circ} \mathrm{E}, 66-72^{\circ} \mathrm{S}\right)$. 

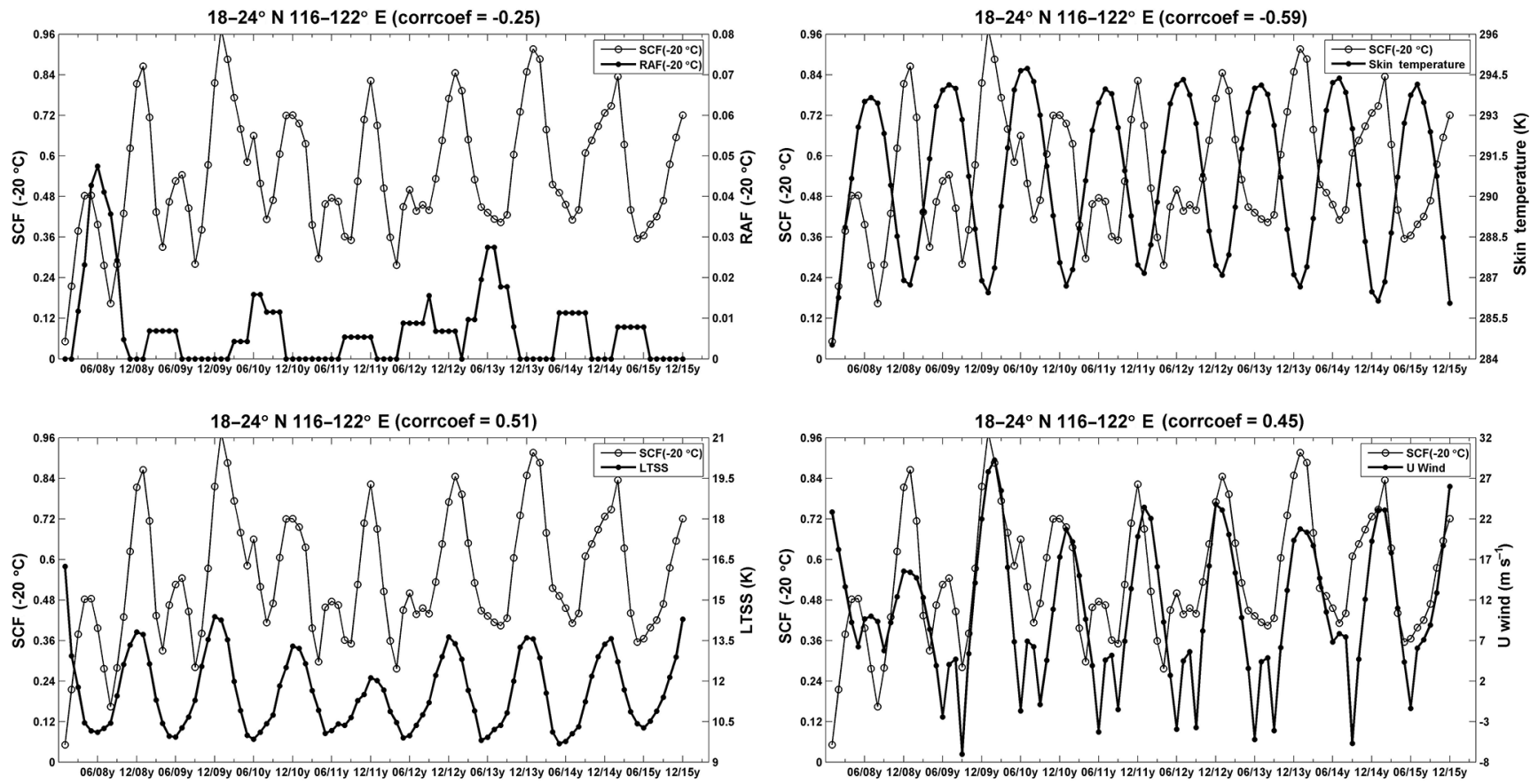

Figure 10. Similar to Fig. 8 but for $-20^{\circ} \mathrm{C}$ isotherm over the subtropics of the Northern Hemisphere $\left(116-122^{\circ} \mathrm{E}, 18-24^{\circ} \mathrm{N}\right)$.
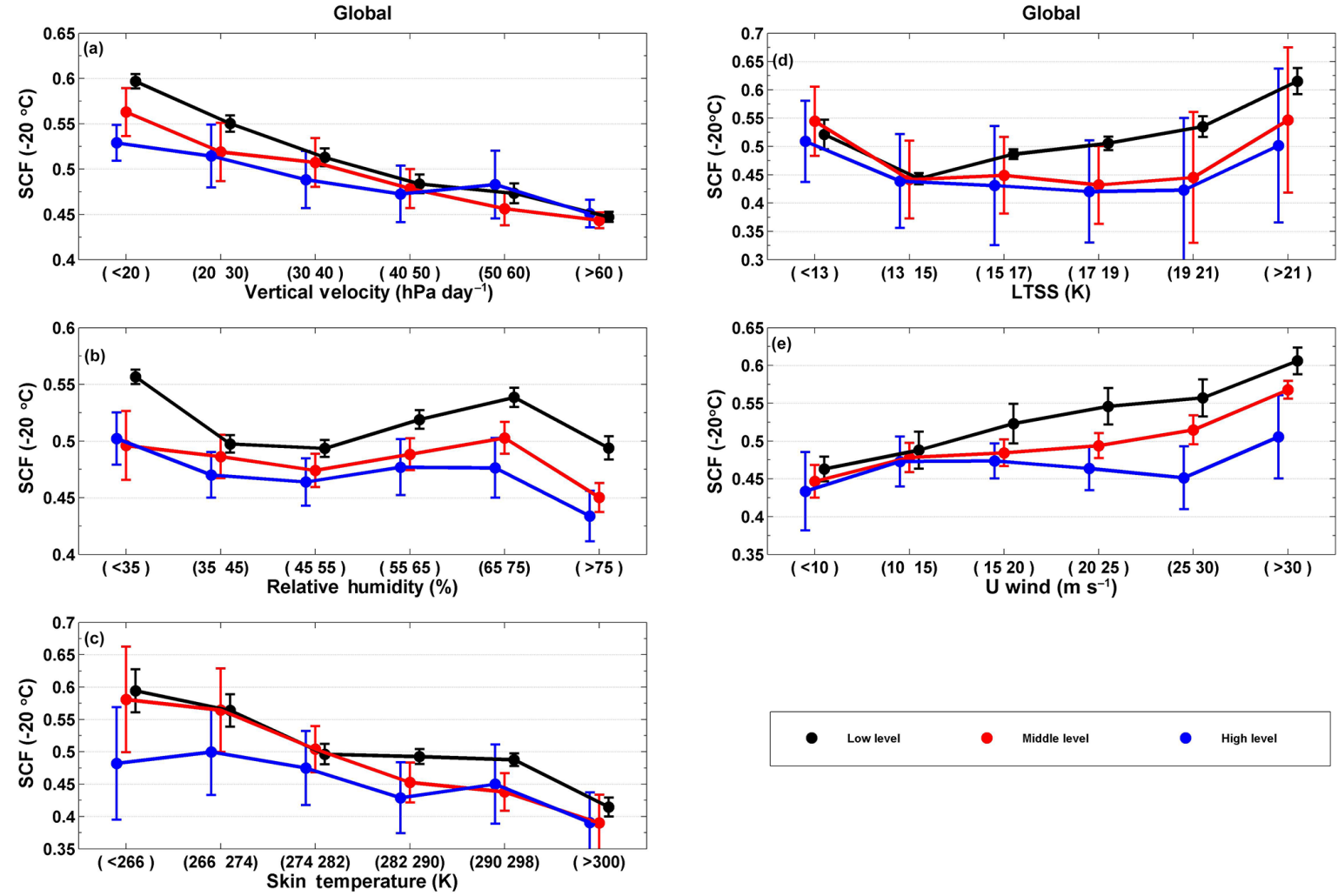

Figure 11. Spatial correlations between SCFs at $-20^{\circ} \mathrm{C}$ isotherm and meteorological parameters under different aerosol loading conditions. Only those regions with temporal correlations between SCFs and meteorological parameters at the $90 \%$ confidence level are used to calculate the spatial correlations between SCFs and meteorological parameters. The correlation coefficients are provided in Table 1. 
Table 1. The summary of spatial correlation coefficients between SCFs and meteorological parameters at three isotherms under different aerosol loading conditions. Only regions with temporal correlations between SCFs and meteorological parameters at the $90 \%$ confidence level are used to calculate the spatial correlations between SCFs and meteorological parameters.

\begin{tabular}{|c|c|c|c|c|c|c|c|c|c|}
\hline \multirow[t]{2}{*}{ Isotherm $\left({ }^{\circ} \mathrm{C}\right)$} & \multicolumn{3}{|c|}{-10} & \multicolumn{3}{|c|}{-20} & \multicolumn{3}{|c|}{-30} \\
\hline & $\mathrm{HAL}^{\mathrm{a}}$ & MAL $^{\mathrm{a}}$ & $\mathrm{LAL}^{\mathrm{a}}$ & HAL & MAL & LAL & HAL & MAL & LAL \\
\hline Velocity & -0.9 & -0.95 & -0.73 & -0.95 & -0.98 & -0.98 & -0.97 & -0.88 & -0.96 \\
\hline RH & $\begin{array}{r}-0.11 \\
P=0.84^{\mathrm{b}}\end{array}$ & $\begin{array}{r}-0.66 \\
P=0.16\end{array}$ & $\begin{array}{r}-0.58 \\
P=0.23\end{array}$ & -0.75 & $\begin{array}{r}-0.47 \\
P=0.34\end{array}$ & $\begin{array}{r}-0.33 \\
P=0.52\end{array}$ & $\begin{array}{r}-0.43 \\
P=0.4\end{array}$ & -0.96 & $\begin{array}{r}-0.65 \\
P=0.16\end{array}$ \\
\hline ST & 0.69 & $\begin{array}{r}-0.31 \\
P=0.55\end{array}$ & $\begin{array}{r}-0.05 \\
P=0.92\end{array}$ & -0.87 & -0.99 & -0.95 & $\begin{array}{r}-0.25 \\
P=0.62\end{array}$ & -0.86 & -0.69 \\
\hline$U$ wind & $\begin{array}{r}-0.62 \\
P=0.2\end{array}$ & 0.81 & 0.78 & $\begin{array}{r}0.61 \\
P=0.2\end{array}$ & 0.94 & 0.98 & $\begin{array}{r}0.43 \\
P=0.4\end{array}$ & 0.86 & 0.85 \\
\hline LTSS & -0.7 & -0.71 & -0.87 & $\begin{array}{r}-0.12 \\
P=0.8\end{array}$ & $P=\begin{array}{r}0.01 \\
0.99\end{array}$ & $\begin{array}{r}0.71 \\
P=0.11\end{array}$ & $\begin{array}{r}0.43 \\
P=0.39\end{array}$ & $\begin{array}{r}0.33 \\
P=0.53\end{array}$ & 0.87 \\
\hline
\end{tabular}

${ }^{a}$ HAL, MAL and LAL are represent the high, middle and low aerosol loading levels; ${ }^{\mathrm{b}}$ We also provide the confidence value (i.e., $p$ value) when the confidence level of the spatial correlation between variables is less than $90 \%$.

firstly with increasing of humidity, then increase gradually, especially under the low aerosol loading condition. Similar to relative humidity, the SCF also decreases firstly with increasing of LTSS, then increases gradually. However, based on the Table 1, it is clear that the spatial correlation coefficients at a global scale between SCFs and relative humidity (or LTSS) are weak and the confidence level is not significant. It further indicates that the same meteorological parameter has a distinct correlation with SCFs in different regions. Obvious spatial correlations also exist between SCFs and zonal wind at $100 \mathrm{hPa}$ (Fig. 11e), especially under low and middle aerosol loading conditions. For example, the spatial correlations between SCFs at $-10^{\circ} \mathrm{C}$ and zonal wind are $-0.62,0.81$ and 0.78 for high, middle and low aerosol loadings, respectively. In summary, strong horizontal wind and low skin temperature (or vertical velocity) correspond to high SCF. In Figs. 2 and 3, we find that the highest SCF does not mean the lowest aerosol frequency over this region (e.g., Southern Ocean). This further indicates that aerosol is not the unique factor to affect the seasonal cycles of SCF. Here, we emphasize that the statistical relationships between SCFs and meteorological parameters are based on the long-term (96 months) datasets to ensure the correlations at the $90 \%$ confidence are robust. From the above analysis and discussion, we are certain that, at least, the variations of SCFs at a given isotherm are obviously correlated with the meteorological parameters, and their correlations depend on regions.

\section{Conclusions and discussion}

Changes in-cloud phase can significantly affect the Earth's radiation budget and global hydrological cycle. Based on the 8 years (2007-2015) of cloud phase information dataset from CALIPSO-GOCCP, aerosol products from CALIPSO and meteorological parameters from the ERA-Interim, this study investigates the effects of atmospheric dynamics on the supercooled liquid cloud fraction during nighttime under different aerosol loadings at a global scale and achieve some new insights in this paper.

Previous studies mainly focused on warm water cloud systems (Li et al., 2011, 2013; Kawamoto and Suzuki, 2012, 2013 ) or dust properties retrieval and simulations (Huang et al., 2010; Bi et al., 2011; Liu et al., 2011) or have demonstrated the importance of dust with respect to cloud properties (Huang et al., 2006b, c, 2014; Su et al., 2008; Wang et al., 2010, 2015, 2016). Some studies have investigated the impact of different aerosol types on cold phase clouds over East Asia (Zhang et al., 2015) or at a global scale (Choi et al., 2010; Tan et al., 2014). However, studies of the statistical relationship between cloud phase changes and meteorological parameters have received far less attention, especially at a global scale. To clarify the roles of different meteorological factors in determining cloud phase changes and further provide observational evidence for the design and evaluation of a more physically based cloud phase partitioning scheme, we perform specially temporal and spatial correlations between SCFs and different meteorological factors on a global scale in this work.

Statistical results indicate that aerosols' effect on nucleation cannot fully explain all SCF changes, especially in those regions where aerosols' effect on nucleation is not a first-order influence (e.g., due to low IN aerosol frequency). The meteorological parameters also play important roles in the SCF variation. However, the statistical relationship between meteorological parameters and SCF is not stable and varies with the different regions. Obviously negative tempo- 
ral correlations between SCFs versus vertical velocity and relative humidity indicate that the higher vertical velocity and relative humidity the smaller SCFs. The smaller SCFs are possibly due to strong precipitation exhausting the large supercooled liquid droplets. However, the impacts of LTSS, skin temperature and horizontal wind on SCFs are relatively complex than those of vertical velocity and humidity. Their temporal correlations with SCFs depend on latitude or surface type. For example, at the $-10^{\circ} \mathrm{C}$ isotherm, negative temporal correlations for skin temperature are mainly located in ocean regions between 30 and $60^{\circ}$ for two hemispheres, whereas positive correlations can be found in the land region of high latitudes. With decreasing temperature (e.g., at the $-20^{\circ} \mathrm{C}$ isotherm), temporal correlation coefficients between SCFs and skin temperature are almost negative in middle and high latitudes. However, it is clear that their temporal correlations vary from positive to negative with decreasing temperature at some special regions (e.g., mainland China). By analyzing the spatial correlations under different aerosol loadings, we find that negative correlations also exist between SCF and the vertical velocity (or surface skin temperature), whereas positive spatial correlations can be found between SCF and the $U$ wind. Recently, evidence has shown that a cloud phase feedback occurs, causing more shortwave to be reflected back out to space relative to the state prior to global warming (McCoy et al., 2014, 2015). Our results, which are based on long-term (96 months) global observations, verify the effects of dynamic factors on cloud phase changes and illustrate that these effects are regional, thus having potential implications for further reducing the biases of climate feedbacks and climate sensitivity among climate models.

\section{Data availability}

The cloud phase product (CALIPSO-GOCCP) is available from the CFMIP-OBS website: ftp: //ftp.climserv.ipsl.polytechnique.fr/cfmip/GOCCP/3D_ CloudFraction/grid_2x2xL40/ (CALIPSO-GOCCP, 2016). The ERA-Interim reanalysis daily $6 \mathrm{~h}$ products are downloaded from the ERA-Interim website: http: //www.ecmwf.int/en/research/climate-reanalysis/era-interim (ERA-Interim, 2016). Aerosol data are obtained from the Atmospheric Science Data Center after registration at https: //eosweb.larc.nasa.gov/project/calipso/aerosol_layer_table, (CALIPSO-Aerosol, 2016).

Competing interests. The authors declare that they have no conflict of interest.

Acknowledgements. This research was jointly supported by the key Program of the National Natural Science Foundation of China (41430425), Foundation for Innovative Research Groups of the National Science Foundation of China (grant no. 41521004), National
Science Foundation of China (grant nos. 41575015, 41305027 and 41375031) and the China 111 project (grant no. B13045). We would like to thank the CALIPSO-GOCCP, CALIPSO and ERA-Interim science teams for providing excellent and accessible data products that made this study possible.

Edited by: J. Quaas

Reviewed by: two anonymous referees

\section{References}

Boucher, O., Randall, D., Artaxo, P., Bretherton,C., Feingold, G., Forster, P., Kerminen, V., Kondo, Y., Liao, H., Lohmann, U., Rasch, P., Satheesh, S. K., Sherwood, S., Stevens, B., and Zhang, X. Y.: Clouds and aerosols, in: Climate Change 2013: The Physical Science Basis. Contribution of Working Group I to the Fifth Assessment Report of the Intergovernmental Panel on Climate Change, edited by: Stocker, T. F., Qin, D., Plattner, G.-K., Tignor, M., Allen, S. K., Boschung, J., Nauels, A., Xia, Y., Bex, V., and Midgley, P. M., 571-657, Cambridge Univ. Press, Cambridge, UK, New York, doi:10.1017/CBO9781107415324, 2013.

Bey, I., Jacob, D. J., Yantosca, R. M., Logan, J. A., Field, B. D., Fiore, A. M., Li, Q., Liu, H. Y., Mickley, L. J., and Schultz, M. G.: Global modeling of tropospheric chemistry with assimilated meteorology: Model description and evaluation, J. Geophys. Res., 106, 23073-23095, doi:10.1029/2001JD000807, 2001.

Bi, J., Huang, J., Fu, Q., Wang, X., Shi, J., Zhang, W., Huang, Z., and Zhang, B.: Toward characterization of the aerosol optical properties over Loess Plateau of Northwestern China, J. Quant. Spectrosc. Ra., 112, D00K17, doi:10.1029/2009JD013372, 2011.

Bodas-Salcedo, A., Webb, M. J., Bony, S., Chepfer, H., Dufresne, J.-L., Klein, S. A., Zhang, Y., Marchand, R., Haynes, J. M., Pincus, R., and John, V. O.: COSP: Satellite simulation software for model assessment, B. Am. Meteorol. Soc., 92, 1023-1043, doi:10.1175/2011BAMS2856.1, 2011.

Bower, K. N., Moss, S. J., Johnson, D. W., Choularton, T. W., Latham, J., Brown, P. R. A., Blyth, A. M., and Cardwell, J.: A parameterization of the ice water content observed in frontal and convective clouds, Q. J. Roy. Meteor. Soc., 122, 1815-1844, 1996.

CALIPSO-Aerosol: CALIPSO level 2, $5 \mathrm{~km}$ aerosol layer product, available at: https://eosweb.larc.nasa.gov/project/calipso/ aerosol_layer_table, last access: 20 December 2016.

CALIPSO-GOCCP: cloud phase product, available at: $\mathrm{ftp} / / / \mathrm{ftp}$.climserv.ipsl.polytechnique.fr/cfmip/GOCCP/3D_ CloudFraction/grid_2x2xL40/, last access: 20 December 2016.

Cesana, G. and Chepfer, H.: How well do climate models simulate cloud vertical structure? - A comparison between CALIPSOGOCCP satellite observations and CMIP5 models, Geophys. Res. Lett., 39, L20803, doi:10.1029/2012GL053153, 2012.

Cesana, G. and Chepfer, H.: Evaluation of the cloud water phase in a climate model using CALIPSO-GOCCP, J. Geophys. Res.Atmos., 118, 7922-7937, doi:10.1002/jgrd.50376, 2013.

Cesana, G., Kay, J. E., Chepfer, H., English, J. M., and de Boer, G.: Ubiquitous low-level liquid-containing Arctic clouds: New observations and climate model constraints 
from CALIPSO-GOCCP, Geophys. Res. Lett., 39, L20804, doi:10.1029/2012GL053385, 2012.

Cesana, G., Waliser, D. E., Jiang, X., and Li, J.-L. F.: Multimodel evaluation of cloud phase transition using satellite and reanalysis data, J. Geophys. Res.-Atmos., 120, 7871-7892, doi:10.1002/2014JD022932, 2015.

Cesana, G., Chepfer, H., Winker, D., Cai, X., Getzewich, B., Okamoto, H., Hagihara, Y., Jourdan, O., Mioche, G., Noel, V., and Reverdy, M.: Using in-situ airborne measurements to evaluate three cloud phase products derived from CALIPSO, J. Geophys. Res.-Atmos., 121, 5788-5808, doi:10.1002/2015JD024334, 2016.

Chepfer, H., Bony, S., Winker, D. M., Chiriaco, M., Dufresne, J.-L., and Seze, G.: Use of CALIPSO lidar observations to evaluate the cloudiness simulated by a climate model, Geophys. Res. Lett., 35, L15704, doi:10.1029/2008GL034207, 2008.

Chepfer, H., Bony, S., Winker, D., Cesana, G., Dufresne, J. L., Minnis, P., Stubenrauch, C. J., and Zeng, S.: The GCM Oriented Calipso Cloud Product (CALIPSO-GOCCP), J. Geophys. Res., 115, D00H16, doi:10.1029/2009JD012251, 2010.

Chepfer, H., Cesana, G., Winker, D., Getzewich, B., Vaughan, M., and Liu, Z.: Comparison of two different cloud climatologies derived from CALIOP Level 1 observations: The CALIPSO-ST and the CALIPSO-GOCCP, J. Atmos. Ocean. Tech., 30, 725744, doi:10.1175/JTECH-D-12-00057.1, 2013.

Choi, Y. S., Lindzen, R. S., Ho, C. H., and Kim, J.: Space observations of cold-cloud phase change, P. Natl. Acad. Sci. USA, 107, 11211-11216, 2010.

Choi, Y.-S., Ho, C.-H., Park, C.-E., Storelvmo, T., and Tan I.: Influence of cloud phase composition on climate feedbacks, J. Geophys. Res.-Atmos., 119, 3687-3700, doi:10.1002/2013JD020582, 2014.

Cziczo, D. J., Froyd, K. D., Hoose, C., Jensen, E. J., Diao, M., Zondlo, M. A., Smith, J. B., Twohy, C. H., and Murphy, D. M.: Clarifying the dominant sources and mechanisms of cirrus cloud formation, Science, 340, 1320-1324, doi:10.1126/science.1234145, 2013.

Dee, D. P., Uppala, S. M., Simmons, A. J., Berrisford, P., Poli, P., Kobayashi, S., Andrae, U., Balmaseda, M. A., Balsamo, G., Bauer, P., Bechtold, P., and Beljaars, A. C. M.: The ERA-Interim reanalysis: Configuration and performance of the data assimilation system, Q. J. Roy. Meteor. Soc., 137, 553-597, 2011.

Delanoe, J. and Hogan, R. J.: Combined CloudSat-CALIPSOMODIS retrievals of the properties of ice clouds, J. Geophys. Res.-Atmos., 115, D00H29, doi:10.1029/2009JD012346, 2010.

ERA-Interim: ERA-Interim reanalysis daily $6 \mathrm{~h}$ products, available at: http://www.ecmwf.int/en/research/climate-reanalysis/ era-interim, last access: 20 December 2016.

Hu, Y., Vaughan, M., Liu, Z., Lin, B., Yang, P., Flittner, D., Hunt, W., Kuehn, R., Huang, J., Wu, D., Rodier, S., Powell, K., Trepte, C., and Winker, D.: The depolarization-attenuated backscatter relation: CALIPSO lidar measurements vs. theory, Opt. Exp., 15, 5327-5332, 2007.

Hu, Y., Winker, D., Vaughan, M., Lin, B., Omar, A., Trepte, C., Flittner, D., Yang, P., Nasiri, S., Baum, B. A., Sun, W., Liu, Z., Wang, Z., Young, S., Stamnes, K., Huang, J., Kuehn, R., and Holz, R. E.: CALIPSO/CALIOP cloud phase discrimination algorithm, J. Atmos. Ocean. Tech., 26, 2206-2309, doi:10.1175/2009JTECHA1280.1, 2009.
Hu, Y., Rodier, S., Xu, K. M., Sun, W., Huang, J., Lin, B., Zhai, P., and Josset, D.: Occurrence, liquid water content, and fraction of supercooled water clouds from combined CALIOP/IIR/MODIS measurements, J. Geophys. Res., 115, D00H34, doi:10.1029/2009JD012384, 2010.

Huang, J. P., Minnis, P., and Lin, B.: Advanced retrievals of multilayered cloud properties using multispectral measurements, J. Geophys. Res., 110, D15S18, doi:10.1029/2004JD005101, 2005.

Huang, J. P., Minnis, P., and Lin, B.: Determination of ice water path in ice-over-water cloud systems using combined MODIS and AMSR-E measurements, Geophys. Res. Lett., 33, L21801, doi:10.1029/2006GL027038, 2006a.

Huang, J. P., Lin, B., Minnis, P., Wang, T., Wang, X., Hu, Y., Yi, Y., and Ayers, J. R.: Satellite-based assessment of possible dust aerosols semi-direct effect on cloud water path over East Asia, Geophys. Res. Lett., 33, L19802, doi:10.1029/2006GL026561, $2006 b$.

Huang, J. P., Minnis, P., Lin, B., Wang, T., Yi, Y., Hu, Y., SunMack, S., and Ayers, K.: Possible influences of Asian dust aerosols on cloud properties and radiative forcing observed from MODIS and CERES, Geophys. Res. Lett., 33, L06824, doi:10.1029/2005GL024724, 2006c.

Huang, J. P., Minnis, P., Chen, B., Huang, Z., Liu, Z., Zhao, Q., Yi, Y., and Ayers, J. K.: Long-range transport and vertical structure of Asian dust from CALIPSO and surface measurements during PACDEX, J. Geophys. Res., 113, D23212, doi:10.1029/2008JD010620, 2008.

Huang, J. P., Wang, T., Wang, W., Li, Z., and Yan, H.: Climate effects of dust aerosols over East Asian arid and semiarid regions, J. Geophys. Res., 119, 11398-11416, doi:10.1002/2014JD021796, 2014.

Huang, Z., Huang, J., Bi, J., Wang, G., Wang, W., Fu, Q., Li, Z., Tsay, S.-C., and Shi, J.: Dust aerosol vertical structure measurements using three MPL lidars during 2008 China-U.S joint dust field experiment, J. Geophys. Res., 115, D00K15, doi:10.1029/2009JD013273, 2010.

Jiang, H., Cotton, W. R., Pinto, J. O., Curry, J. A., and Weissbluth, M. J.: Cloud resolving simulations of mixed-phase Arctic stratus observed during BASE: Sensitivity to concentration of ice crystals and large-scale heat and moisture advection, J. Atmos. Sci., 57, 2105-2117, 2000.

Kawamoto, K. and Suzuki, K.: Microphysical transition in water clouds Over the Amazon and China derived from spaceborne radar and Radiometer data, J. Geophys. Res., 117, D05212, doi:10.1029/2011JD016412, 2012.

Kawamoto, K. and Suzuki, K.: Comparison of water cloud microphysics over mid-latitude land and ocean using CloudSat and MODIS observations, J. Quant. Spectrosc. Ra., 122, 13-24, 2013.

Klein, S. A. and Hartmann, D. L.: The seasonal cycle of low stratiform clouds, J. Climate, 6, 1588-1606, 1993.

Li, J., Yi, Y., Minnis, P., Huang, J., Yan, H., Ma, Y., Wang, W., and Ayers, J. K.: Radiative effect differences between multilayered and single-layer clouds derived from CERES, CALIPSO, and CloudSat data, J. Quant. Spectrosc. Ra., 112, 361-375, doi:10.1016/j.jqsrt.2010.10.006, 2010.

Li, J., Hu, Y., Huang, J., Stamnes, K., Yi, Y., and Stamnes, S.: A new method for retrieval of the extinction coefficient of water clouds 
by using the tail of the CALIOP signal, Atmos. Chem. Phys., 11, 2903-2916, doi:10.5194/acp-11-2903-2011, 2011.

Li, J., Yi, Y. H., Stamnes, K., Ding, X. D., Wang, T. H., Jin, H. C., and Wang, S. S.: A new approach to retrieve cloud base height of marine boundary layer clouds, Geophys. Res. Lett., 40, 44484453, doi:10.1002/grl.50836, 2013.

Li, J., Huang, J., Stamnes, K., Wang, T., Lv, Q., and Jin, H.: A global survey of cloud overlap based on CALIPSO and CloudSat measurements, Atmos. Chem. Phys., 15, 519-536, doi:10.5194/acp15-519-2015, 2015.

Liu, Y., Huang, J., Shi, G., Takamura, T., Khatri, P., Bi, J., Shi, J., Wang, T., Wang, X., and Zhang, B.: Aerosol optical properties and radiative effect determined from sky-radiometer over Loess Plateau of Northwest China, Atmos. Chem. Phys., 11, 1145511463, doi:10.5194/acp-11-11455-2011, 2011.

Liu, Z., Vaughan, M., Winker, D., Kittaka, C., Getzewich, B., Kuehn, R., Omar, A., Powell, K., Trepte, C., and Hostetler, C.: The CALIPSO lidar cloud and aerosol discrimination: Version 2 algorithm and initial assessment of performance, J. Atmos. Ocean. Tech., 26, 1198-1213, doi:10.1175/2009JTECHA1229.1, 2009.

Lv, Q., Li, J., Wang, T., and Huang, J.: Cloud radiative forcing induced by layered clouds and associated impact on the atmospheric heating rate, J. Meteor. Res., 29, 779-792, doi:10.1007/s13351-015-5078-7, 2015.

Lohmann, U. and Feichter, J.: Global indirect aerosol effects: a review, Atmos. Chem. Phys., 5, 715-737, doi:10.5194/acp-5-7152005, 2005.

McCoy, D. T., Hartmann, D. L., and Grosvenor, D. P.: Observed Southern Ocean Cloud Properties and Shortwave Reflection Part 2: Phase changes and low cloud feedback, J. Climate, 27, 88588868, doi:10.1175/JCLI-D-14-00288.1, 2014.

McCoy, D. T., Hartmann, D. L., Zelinka, M. D., Ceppi, P., and Grosvenor, D. P.: Mixed-phase cloud physics and Southern Ocean cloud feedback in climate models, J. Geophys. Res.Atmos., 120, doi:10.1002/2015JD023603, 9539-9554, 2015.

Mielonen, T., Arola, A., Komppula, M., Kukkonen, J., Koskinen, J., de Leeuw, G., and Lehtinen, K. E. J.: Comparison of CALIOP level 2 aerosol subtypes to aerosol types derived from AERONET inversion data, Geophys. Res. Lett., 36, L18804, doi:10.1029/2009GL039609, 2009.

Moeng, C.-H.: Entrainment rate, cloud fraction, and liquid water path of PBL stratocumulus cloud, J. Atmos. Sci., 57, 3627-3643, doi:10.1175/1520-0469(2000)057<3627:ERCFAL>2.0.CO;2, 2000.

Naud, C. M., Del Genio, A. D., and Bauer, M.: Observational constraints on the cloud thermodynamic phase in midlatitude storms, J. Climate, 19, 5273-5288, 2006.

Niedermeier, D., Hartmann, S., Clauss, T., Wex, H., Kiselev, A., Sullivan, R. C., DeMott, P. J., Petters, M. D., Reitz, P., Schneider, J., Mikhailov, E., Sierau, B., Stetzer, O., Reimann, B., Bundke, U., Shaw, R. A., Buchholz, A., Mentel, T. F., and Stratmann, F.: Experimental study of the role of physicochemical surface processing on the IN ability of mineral dust particles, Atmos. Chem. Phys., 11, 11131-11144, doi:10.5194/acp-11-11131-2011, 2011.

Noel, V. and Chepfer, H.: A global view of horizontally oriented crystals in ice clouds from Cloud-Aerosol Lidar and Infrared Pathfinder Satellite Observation (CALIPSO), J. Geophys. Res., 115, D00H23, doi:10.1029/2009JD012365, 2010.
Omar, A. H., Winker, D. M., Vaughan, M. A., Hu, Y., Trepte, C. R., Ferrare, R. A., Lee, K.-P., Hostetler, C. A., Kittaka, C., Rogers, R. R., Kuehn, R. E., and Liu, Z.: The CALIPSO automated aerosol classification and lidar ratio selection algorithm, J. Atmos. Ocean. Tech., 26, 1994-2014, doi:10.1175/2009JTECHA1231.1, 2009.

Pinto, J. O.: Autumnal mixed-phase cloudy boundary layers in the Arctic, J. Atmos. Sci., 55, 2016-2038, 1998.

Pruppacher, H. R. and Klett, J. D.:Microphysics of Clouds and Precipitation, 2nd ed., 954 pp., Kluwer Acad., Dordrecht, Netherlands, 1997.

Rauber, R. M. and Tokay, A.: An explanation for the existence of supercooled water at the top of cold clouds, J. Atmos. Sci., 48, 1005-1023, 1991.

Sassen, K. and Khvorostyanov, V. I.: Microphysical and radiative properties of mixed phase altocumulus: a model evaluation of glaciation effects, Atmos. Res., 84, 390-398, 2007.

Shupe, M. D., Matrosov, S. Y., and Uttal, T.: Arctic mixed-phase cloud properties derived from surface-based sensors at SHEBA, J. Atmos. Sci., 63, 697-711, 2006.

Shupe, M. D., Kollias, P., Persson, P. O. G., and McFarquhar, G. M.: Vertical motions in arctic mixed phase stratus, J. Atmos. Sci., 65, 1304-1322, 2008.

Stephens, G. L., Vane, D. G., Boain, R. J., Mace, G. G., Sassen, K., Wang, Z., Illingworth, A. J., O’Connor, E. J., Rossow, W. B., Durden, S. L., Miller, S. D., Austin, R. T., Benedetti, A., Mitrescu, C., and CloudSat Science Team: The CloudSat mission and the A-Train, A new dimension of space-based observations of clouds and precipitation, B. Am. Meteorol. Soc., 83, 17711790, 2002.

Su, J., Huang, J., Fu, Q., Minnis, P., Ge, J., and Bi, J.: Estimation of Asian dust aerosol effect on cloud radiation forcing using FuLiou radiative model and CERES measurements, Atmos. Chem. Phys., 8, 2763-2771, doi:10.5194/acp-8-2763-2008, 2008.

Sun, Z. and Shine, K. P.: Studies of the radiative properties of ice and mixed-phase clouds, Q. J. Roy. Meteor. Soc., 120, 111-137, 1994.

Tan, I., Storelvmo, T., and Choi, Y. S.: Spaceborne lidar observations of the ice-nucleating potential of dust, polluted dust and smoke aerosols in mixed-phase clouds, J. Geophys. Res.-Atmos., 119, 6653-6665, doi:10.1002/2013JD021333, 2014.

Tan, I., Storelvmo, T., and Zelinka, M. D.: Observational constraints on mixed-phase clouds imply higher climate sensitivity, Science, 352, 224-227, 2016.

Tremblay, A., Glazer, A., Yu, W., and Benoit, R.: A mixed-phase cloud scheme based on a single prognostic equation, Tellus, 48A, 483-500, 1996.

Tsushima, Y., Emori, S., Ogura, T., Kimoto, M., Webb, M. J., Williams, K. D., Ringer, M. A., Soden, B. J., Li, B., and Andronova, N.: Importance of the mixed phase cloud distribution in the control climate for assessing the response of clouds to carbon dioxide increase: a multi-model study, Clim. Dynam., 27, 113126, 2006.

Wang, W., Huang, J., Minnis, P., Hu, Y., Li, J., Huang, Z., Ayers, J. K., and Wang, T.: Dusty cloud properties and radiative forcing over dust source and downwind regions derived from A-Train data during the Pacific Dust Experiment, J. Geophys. Res., 115, D00H35, doi:10.1029/2010JD014109, 2010. 
Wang, W., Sheng, L., Jin, H., and Han, Y.: Dust Aerosol Effects on Cirrus and Altocumulus Clouds in Northwest China, J. Meteor. Res., 29, 793-805, 2015.

Wang, W., Sheng, L., Dong, X., Qu, W., Sun, J., Jin, H., and Logan, T.: Dust aerosol impact on the retrieval of cloud top height from satellite observations of CALIPSO, CloudSat and MODIS, J. Quant. Spectrosc. Ra., 188, 132-141, doi:10.1016/j.jqsrt.2016.03.034, 2016.

West, R. E. L., Stier, P., Jones, A., Johnson, C. E., Mann, G. W., Bellouin, N., Partridge, D. G., and Kipling, Z.: The importance of vertical velocity variability for estimates of the indirect aerosol effects, Atmos. Chem. Phys., 14, 6369-6393, doi:10.5194/acp14-6369-2014, 2014.

Westbrook, C. D., Illingworth, A. J., O’Connor, E. J., and Hogan, R. J.: Doppler lidar measurements of oriented planar ice crystals falling from supercooled and glaciated layer clouds, Q. J. Roy. Meteor. Soc., 136, 260-276, 2010.
Winker, D. M., Hunt, W. H., and Mcgill, M. J.: Initial performance assessment of CALIOP, Geophys. Res. Lett., 34, L19803, doi:10.1029/2007GL030135, 2007.

Zhang, D., Wang, Z., and Liu, D.: A global view of midlevel liquidlayer topped stratiform cloud distribution and phase partition from CALIPSO and CloudSat measurements, J. Geophys. Res., 115, D00H13, doi:10.1029/2009JD012143, 2010.

Zhang, D., Liu, D., Luo, T., Wang, Z., and Yin, Y.: Aerosol impacts on cloud thermodynamic phase change over East Asia observed with CALIPSO and CloudSat measurements, J. Geophys. Res.Atmos., 120, 1490-1501, doi:10.1002/2014JD022630, 2015. 